\title{
Contribution of neuroinflammation and immunity to brain aging and the mitigating effects of physical and cognitive interventions
}

\author{
Svetlana Di Benedetto ${ }^{\mathrm{a}, \mathrm{b}}$, Ludmila Müller ${ }^{\mathrm{a}, *}$, Elisabeth Wenger $^{\mathrm{a}}$, Sandra Düzel $^{\mathrm{a}}$, \\ Graham Pawelec ${ }^{\mathrm{b}}$ \\ a Max Planck Institute for Human Development, Center for Lifespan Psychology, Lentzeallee 94, 14195, Berlin, Germany \\ ${ }^{\mathrm{b}}$ Center for Medical Research, Department of Internal Medicine II, University of Tübingen, Waldhörnlestr. 22, 72072 Tübingen, Germany
}

\section{A R T I C L E I N F O}

\section{Article history:}

Received 2 December 2016

Received in revised form 24 January 2017

Accepted 30 January 2017

Available online 1 February 2017

\section{Keywords:}

Aging

Brain

Immunosenescence

Inflammaging

Neuroplasticity

Neuroinflammation

Cytokines

T cells

Microglia

Neurotrophic factors

Cognition

Physical exercise

Cognitive intervention

\begin{abstract}
A B S T R A C T
It is widely accepted that the brain and the immune system continuously interact during normal as well as pathological functioning. Human aging is commonly accompanied by low-grade inflammation in both the immune and central nervous systems, thought to contribute to many age-related diseases. This review of the current literature focuses first on the normal neuroimmune interactions occurring in the brain, which promote learning, memory and neuroplasticity. Further, we discuss the protective and dynamic role of barriers to neuroimmune interactions, which have become clearer with the recent discovery of the meningeal lymphatic system. Next, we consider age-related changes of the immune system and possible deleterious influences of immunosenescence and low-grade inflammation (inflammaging) on neurodegenerative processes in the normally aging brain. We survey the major immunomodulators and neuroregulators in the aging brain and their highly tuned dynamic and reciprocal interactions. Finally, we consider our current understanding of how physical activity, as well as a combination of physical and cognitive interventions, may mediate anti-inflammatory effects and thus positively impact brain aging.
\end{abstract} (c) 2017 Elsevier Ltd. All rights reserved.

\section{Contents}

1. Introduction .

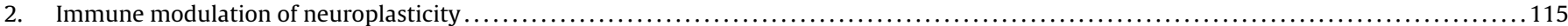

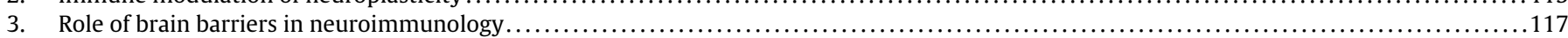

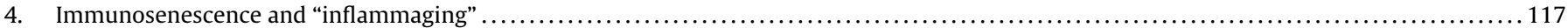

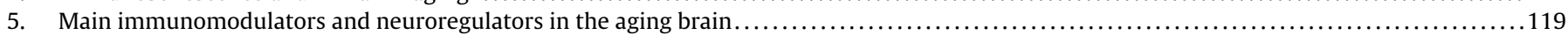

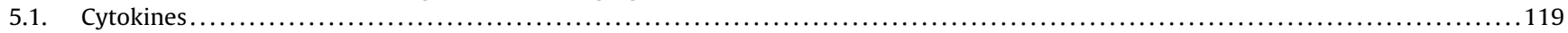

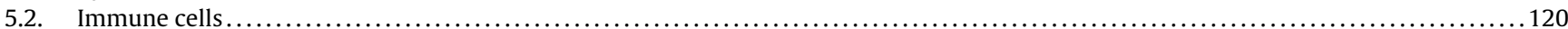

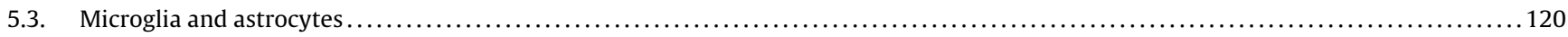

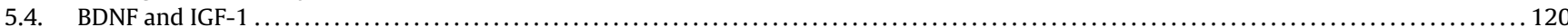

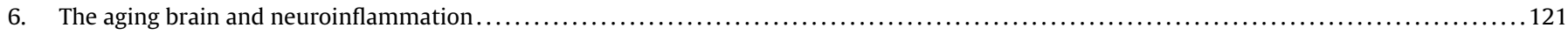

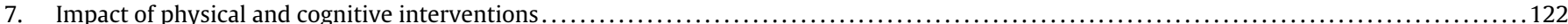

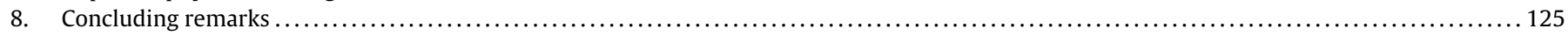

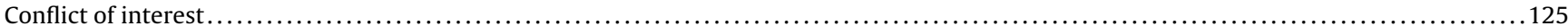

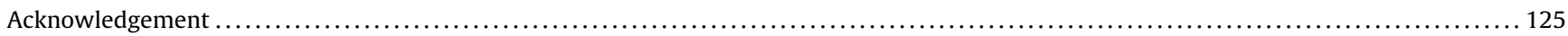

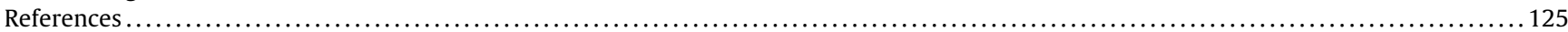

\footnotetext{
* Corresponding author.

E-mail address: lmueller@mpib-berlin.mpg.de (L. Müller).
} 


\section{Introduction}

For many years the brain was considered as an immuneprivileged space, functioning fully autonomically in isolation from the immune system, separated by a relatively impenetrable bloodbrain barrier. However, recent findings are resulting in a radical shift in this view. First, it used to be believed that the brain has no lymphatic system, reflecting lack of entry of lymphocytes into this sensitive area. The appearance of immune cells in the brain was considered an exceptionally harmful pathological incident leading to neurodegeneration. Second, for many years, neurogenesis was thought to be restricted to embryonic and developmental stages, but this view is now also being revised following the discovery of adult neurogenesis. It is now well-accepted that the brain is plastic and actually capable of change throughout the lifespan, adapting its function to different external and internal demands by altering its structure (Lövdén et al., 2013). The term "neuroplasticity" encompasses the potential for a number of functional and structural mechanisms, regulated by diverse extrinsic and intrinsic cues, all of which allow neuronal remodeling, formation of novel synapses and birth of new neurons (Calabrese et al., 2014). The immune system actively participates in this process, and immune cells and their secreted mediators can modulate adult neurogenesis under both homeostatic conditions and in phases of remodeling (Aimone et al., 2014; Kempermann et al., 2002; Leiter et al., 2016; Singhal et al., 2014; Villeda et al., 2011; Yau et al., 2015; Yirmiya and Goshen, 2011; Ziv et al., 2006).

The central nervous system (CNS) is no longer considered as being restricted to limited interactions with the peripheral immune system. We now know that these two major physiological systems communicate with each other constantly and extensively through multiple pathways (Ellwardt et al., 2016; Quan and Banks, 2007). Recent technological advances allow us to address this crosstalk using such techniques as brain imaging, cell-specific targeting and sequencing. Animal models have additionally helped to shed light on the complex mechanisms of neuroimmune regulation (Berry et al., 2010; Capoccia et al., 2013; Veiga-Fernandes and Mucida, 2016). Scientific interest in these interactions has markedly increased since the discovery of a meningeal lymphatic system capable of carrying fluid, immune cells, and macromolecules from the CNS to the draining lymph nodes (Louveau et al., 2015; Raper et al., 2016).

It could be postulated that the immune system and CNS represent the two major adaptive systems of the body. In this context, chronic inflammation can be regarded as a result of the maladjustment of these two major adaptive systems to resolve acute inflammation, which in turn may affect the course of the aging process (Elenkov et al., 2005). The interplay between aging, genetic predisposition, and environmental exposures initiates systemic and local metabolic changes as well as inflammatory reactions that predispose an individual to neuropsychiatric and neurodegenerative diseases (Deleidi et al., 2015). Even conditions of the prenatal environment (such as maternal chronic stress) may have longterm consequences influencing postnatal development (Berry et al., 2015). Maternal obesity may already prove detrimental by providing an intrauterine environment with elevated glucocorticoids, insulin resistance and increased inflammation that influences fetal developmental pathways associated with unhealthy aging in later life (Hanson and Gluckman, 2014; Holvoet, 2012; Iozzo et al., 2014).

The focus of the present review is on neuroimmune interactions in "normal" aging, which have received relatively little attention, rather than neurodegenerative pathologies, which have been extensively reviewed recently (Da Mesquita et al., 2016; Feigenson et al., 2014; Goldeck et al., 2016; Hansel et al., 2010; Leza et al., 2015; Litteljohn et al., 2014; Na et al., 2014; Norden et al., 2015; Nunes et al., 2013; Swardfager et al., 2016; Tansey, 2010; Tansey and Goldberg, 2010; von Bernhardi et al., 2010). Thus, we summarize representative studies and reviews concerning the multitude of reciprocal and dynamic communications between the nervous and immune systems during normal aging, the systemic consequences of age-related dysfunction of these communications, and possible interventions to mitigate this process. First, we will introduce the neuroimmunomodulatory mechanisms involved in the process of learning and memory under normal conditions, and then discuss their dysregulation in aging.

\section{Immune modulation of neuroplasticity}

The immune system communicates constantly with the CNS and is involved in modulating behavior and in many other critical neurological functions throughout the lifespan (Wilson et al., 2002). Normal learning and memory processes are dependent on hippocampal neurogenesis and deficits in such processes may lead to impairments in both spatial and non-spatial learning tasks (Yau et al., 2015). It has been well established that hippocampal neurogenesis in the adult brain is regulated by various intrinsic and extrinsic mechanisms (Kempermann et al., 2002). One of the mechanisms for optimal hippocampal neurogenesis is dependent on the immune system, an unexpected finding first demonstrated in mice with severe combined immune deficiency (SCID mice) and in mice lacking certain immune cell populations (Brynskikh et al., 2008; Kipnis et al., 2004; Wolf et al., 2009; Ziv et al., 2006). The role of systemic immune cells in supporting brain function and plasticity has been demonstrated for hippocampus-dependent functions such as spatial memory and sensorimotor gating (Kipnis et al., 2004; Ron-Harel et al., 2011; Wolf et al., 2009). Remarkably, it was found that systemic depletion of $\mathrm{CD} 4^{+} \mathrm{T}$ lymphocytes led to significantly reduced hippocampal neurogenesis, impaired reversal learning in the Morris water maze, and decreased brainderived neurotrophic factor (BDNF) expression in the brain (Wolf et al., 2009). Repopulation with $\mathrm{CD}^{+} \mathrm{T}$ cells restored the deficits observed in immune-deficient mice, highlighting the role of this T-cell population as being pro-neurogenic under physiological conditions (Leiter et al., 2016). Apparently, hippocampus-dependent cognitive ability is supported by CNS-specific T cells, which accumulate within the brain meningeal spaces and produce interleukin (IL)-4, inducing BDNF production (Fig. 1) during the performance of cognitive tasks (Derecki et al., 2010). CD4 ${ }^{+}$T cells were shown to promote and maintain neurogenesis by positively influencing microglia and regulating insulin-growth factor (IGF)-1 transport into the brain, thereby also regulating BDNF levels (Wekerle, 2006; Ziv et al., 2006). CNS-specific $\mathrm{CD}^{+}{ }^{+} \mathrm{T}$ cells are thought to be stimulated by macrophages, which circulate through the brain parenchyma, phagocytizing and processing CNS-derived selfantigens, such as myelin and/or neural debris. They are able to present these processed antigens and to stimulate naïve $T$ cells in the periphery, resulting in the development of CNS-specific memory T cells (Fig. 1, bottom left), which later appear in the meningeal cerebrospinal fluid (CSF). Here they can be re-stimulated by brainsurveying macrophages (Fig. 1, top left) to produce neuroprotective cytokines and neurotrophic factors, supporting normal cognitive performance, learning and memory (Ron-Harel et al., 2011). T cells found in the CSF are mostly of central memory phenotype, expressing CCR7, CD27 and the activation marker CD69 (Ellwardt et al., 2016), in contrast to those within the choroid plexus (CP), which appear to be of effector-memory type (Baruch and Schwartz, 2013). Cytokines secreted by T cells, such as IL- 4 and transforming growth factor $\beta$ (TGF- $\beta$ ), have a protective effect on neurons and neural precursor cells (Fig. 1, central). Additionally, IL-4 stimulates microglia to produce BDNF, IGF-1, TGF- $\beta$, which all influence neuronal functioning (Burch, 2014; Ellwardt et al., 2016). IL-4 also 


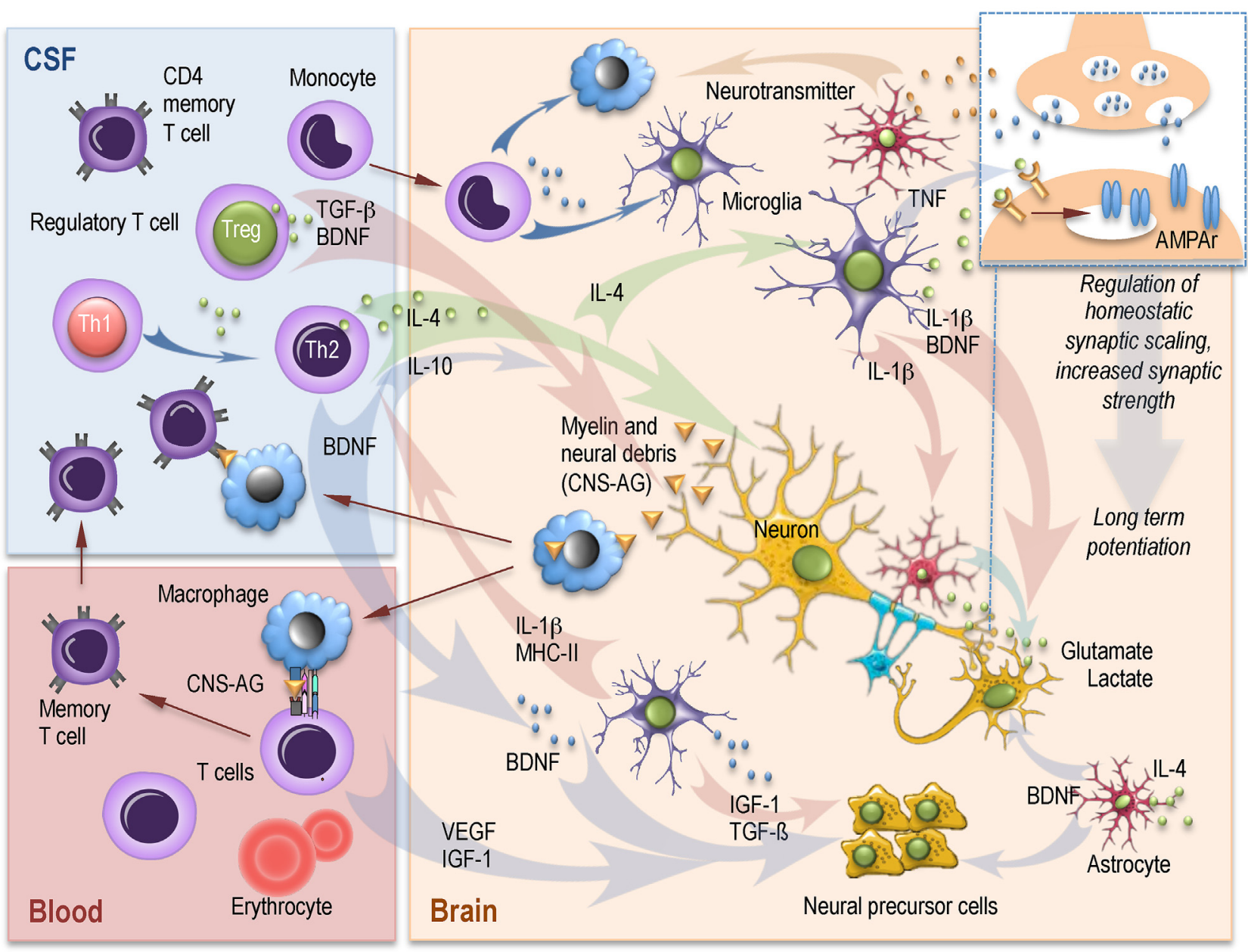

Fig. 1. Immune maintenance of brain homeostasis.

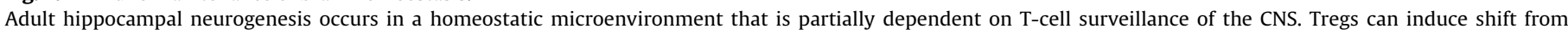

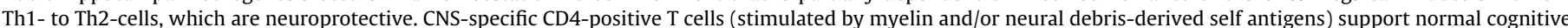

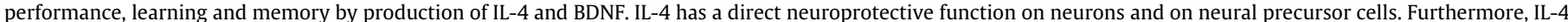

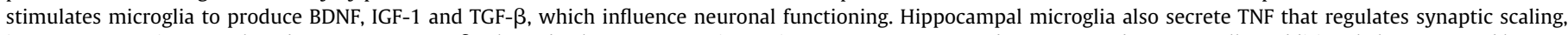

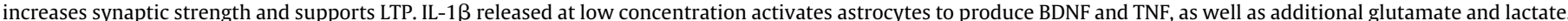

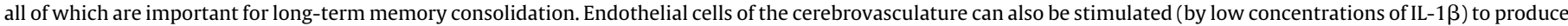

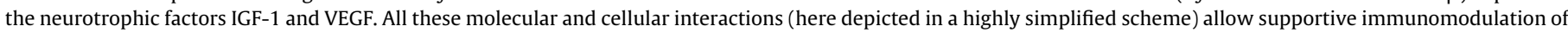
brain function, neurogenesis and plasticity.

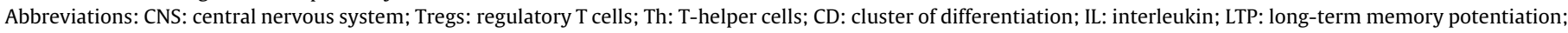

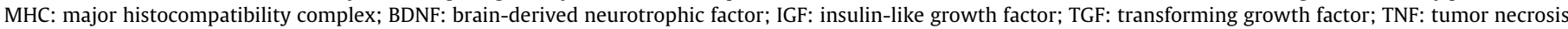
factor; VEGF: vascular endothelial growth factor.

promotes astrocyte expression of BDNF that is crucial for learning and cognition (Ron-Harel et al., 2011). Infiltrating macrophages also play an important role in maintaining homeostatic conditions in the brain (Fig. 1, central). Together with glial cells they regulate the physiological milieu of the brain by removing dead cells and cell debris, buffering toxic compounds and producing growth factors needed for cell survival and renewal, and also by down-regulating pro-inflammatory factors such as IL- $1 \beta$ and tumor necrosis factor (TNF) (Shechter et al., 2009). Microglial expression of major histocompatibility complex (MHC) class II molecules and of IL$1 \beta$ (at low levels) can induce $\mathrm{T}$ cells to communicate with glia and meningeal myeloid cells via production of IL-4. Endothelial cells of the cerebrovasculature can also be stimulated by low concentrations of IL-1 $\beta$ to produce neurotrophic factors IGF-1 and vascular endothelial growth factor (VEGF) (Goshen and Yirmiya, 2009; Wohleb and Delpech, 2016; Yirmiya and Goshen, 2011). VEGF stimulates precursor cell proliferation in the subgranular zone and has neurogenic and angiogenic properties (Leiter et al., 2016).
Regulatory T cells (Treg) were also shown to modulate neuroinflammation by inducing apoptosis in pro-inflammatory M1-type glia, thereby promoting the neuroprotective M2 phenotype. They also decrease neurotoxicity by inhibition of glutamate secretion and generation of reactive oxygen species (ROS). Additionally, regulatory $\mathrm{T}$ cells (Fig. 1 , top left) can induce a Th1-to-Th2 shift by down-regulating Th1 cytokine-producing $\mathrm{T}$ cells, and up-regulating Th2 cytokine-producing $\mathrm{T}$ cells, which are neuroprotective (Ellwardt et al., 2016; Kipnis et al., 2012; Xie et al., 2015).

Although most studies have reported deleterious effects of TNF on synaptic plasticity, it was also shown that physiologically low levels of TNF might be important in brain development (Stellwagen and Malenka, 2006). At glutamatergic synapses, plasticity usually requires changes in the number of postsynaptic $\alpha$-amino-3-hydroxy-5-methyl-4-isoxazolepropionic acid (AMPA) receptors (Bains and Oliet, 2007). The TNF secreted by hippocampal microglia is crucial for synaptic plasticity (Fig. 1, top right) underlying higher brain functions. It regulates synaptic scaling, increases synaptic strength and supports long-term potentiation (LTP, which 
is known to reflect a long-lasting increase in synaptic efficacy). This is thought to be an important underlying mechanism of learning and memory formation (Baune et al., 2008; Beattie et al., 2002; Stellwagen and Malenka, 2006). The TNF released from microglia in response to decreased neuronal activity up-regulates the number of synaptic AMPA receptors, and thus synaptic strength, allowing the homeostatic adjustment of neuronal excitability (Bains and Oliet, 2007; Stellwagen and Malenka, 2006).

Like TNF, also IL-1 $\beta$ has a dual role: when released at low concentrations and under homeostatic conditions, IL-1 $\beta$ activates astrocytes to produce BDNF and TNF, as well as additional glutamate and lactate, all of which are important for long-term memory consolidation (Goshen et al., 2008; Goshen and Yirmiya, 2009). Goshen and colleagues demonstrated that physiological levels of IL-1 $\beta$ support memory formation, such that a slight increase in its level can even improve memory (Goshen and Yirmiya, 2009). However, any deviation from this physiological range results in impaired memory formation.

In the next section we will consider the important role of brain barriers in the dynamic regulation and maintenance of brain homeostasis and pursue the question of which mechanisms allow this vital cross communication between the CNS and immune system.

\section{Role of brain barriers in neuroimmunology}

Under homeostatic conditions the brain parenchyma is physically separated from the peripheral milieu by sophisticated cellular structures that are not only responsible for maintaining brain homeostasis but also for specific communication with other systems outside the CNS (Banks, 2015; Da Mesquita et al., 2016; Stolp et al., 2013). In fact, the question of how peripheral immune cells, cytokines and other immune mediators can affect a central behavioral response arose a long time ago. The first possible explanation was provided by invoking the activity of existing circumventricular regions of the brain, where the blood-brain barrier (BBB) is less impenetrable (such as the organum vasculosum lateralis terminalis, OVLT) and allows for direct entry (Maier et al., 1998). Additionally, for immune mediators like TNF, IL-1 and soluble IL-1-receptors, specific active transport mechanisms have been described (Dunn, 1992; Gutierrez et al., 1993, 1994). Moreover, binding of cytokines to endothelial receptors of the cerebrovasculature with subsequent release of other mediators (such as chemokines, endothelial cell adhesion molecules, prostaglandins and nitric oxide) leads to impairment of BBB integrity (Anthony et al., 1997) and allows entry into the brain.

Other mechanisms that may allow activated $\mathrm{T}$ cells to cross the BBB could be dependent on molecules such as P-selectin (Hickey, 2000). Peripheral cytokines crossing the BBB can also act indirectly by inducing release of more cytokine from brain stores (Banks, 2015). An alternative route by which the immune system might communicate with the CNS is via direct cytokine stimulation of vagal sensory nerve activity or via the sympathetic nervous system (Hansen et al., 2000; Hansen et al., 1998). Apparently, cytokine stimulation of peripheral sensory neural afferents induces central cytokine production or central alterations in neurotransmission (Hasegawa-Ishii et al., 2016).

In the following, we briefly describe the structure and function of the three main barriers of the brain depicted in Fig. 2:

(i) The BBB is formed by highly specialized, low pinocytotic endothelial cells, which line brain capillaries and are connected by tight junctions (Fig. 2, bottom right). At the interface between blood and brain, these tight junctions restrict the passage of solutes. Endothelial cells utilize different mechanisms to transduce signals from the vascular system and from the brain, described in more detail in the previous paragraph. The endothelial layer is surrounded by pericytes, astrocytic endfeet, and branches of circulating microglia. Together with the neural and dendritic processes they constitute the neurovascular unit that allows responses to external alterations in a very rapid and dynamic manner (Da Mesquita et al., 2016). The complex interplay between endothelial cells, astrocytes and brain cells as well as between endothelial cells and blood-derived immune cells is necessary to create a dynamic and protective blood-brain barrier. The BBB allows the controlled, regulated exchange of chemokines, cytokines, and immune cells between the CNS and the blood, as well as the secretion of immunomodulatory molecules by the BBB itself (Banks, 2015; Engelhardt et al., 2016; Quan and Banks, 2007; Shechter et al., 2013).

(ii) The blood-CSF barrier (BCSFB) is formed by tight junctions between epithelial cells of the choroid plexus (Fig. 2, bottom left). The $\mathrm{CP}$ contains a single layer of epithelium (with numerous microvilli) surrounding the inner stroma and blood vessels, with the endothelial layer of the latter being fenestrated. The $\mathrm{CP}$ is responsible for the production of CSF, providing a nutrientrich milieu, and participating in brain homeostasis. CP regulates transport of serum-derived substances and immune cells across its epithelial layer. In contrast to the BBB, the BCSF barrier is permeable to immune cells also under normal conditions, allowing immunosurveillance (Plata-Salaman, 1991; Ron-Harel et al., 2011; Shechter et al., 2013).

Recent studies have recognized the $\mathrm{CP}$ as an active immunological interface and an important neuroimmune compartment in maintaining and restoring brain homeostasis. The $\mathrm{CP}$ is enriched with CNS-specific T cells and is strategically positioned for signal exchange between the CNS (through CSF) and circulation (through epithelium-immune cell interactions) participating in modulating brain functions (Baruch and Schwartz, 2013).

(iii) The CSF-brain barrier (CSFBB) at the level of the pia arachnoid is formed by tight junctions between endothelial cells of the arachnoid vessels (Fig. 2, top left). The recent discovery of functional classic lymphatic vessels (LV) in this area has opened a new window for understanding neuroimmune interactions within the CNS (Engelhardt et al., 2016; Raper et al., 2016; Shechter et al., 2013). The meningeal lymphatic system emerged as a new player in these interactions. It is hypothesized that the main role of the meningeal lymphatic system is not the drainage of the water content of the CSF, but rather a more pronounced immunological function, such as drainage of macromolecules and immune cells into cervical lymph nodes to maintain brain immune surveillance (Raper et al., 2016).

\section{Immunosenescence and "inflammaging"}

As we age, our immune system undergoes an impreciselydefined process of "immunosenescence" that affects both adaptive and innate immune systems. Monocytes, which are innate immune cells, are known to be mediators of the inflammatory response and comprise at least three different subsets, based on their expression of CD14 (a pattern recognition receptor binding microorganism-derived lipopolysaccharide) and CD16 (a low affinity receptor for the Fc portion of immunoglobulins), namely classical, intermediate and non-classical monocytes. An age-related increase in frequencies of intermediate and nonclassical monocytes has been reported (de Pablo-Bernal et al., 2016; Hearps et al., 2012). Our results from the Berlin Aging Study II confirmed these findings, where we also found an agerelated increase in frequencies of intermediate and non-classical monocytes (unpublished results). It has been suggested that aging is associated with chronic innate immune activation and significant changes in monocyte functions, which may have impli- 


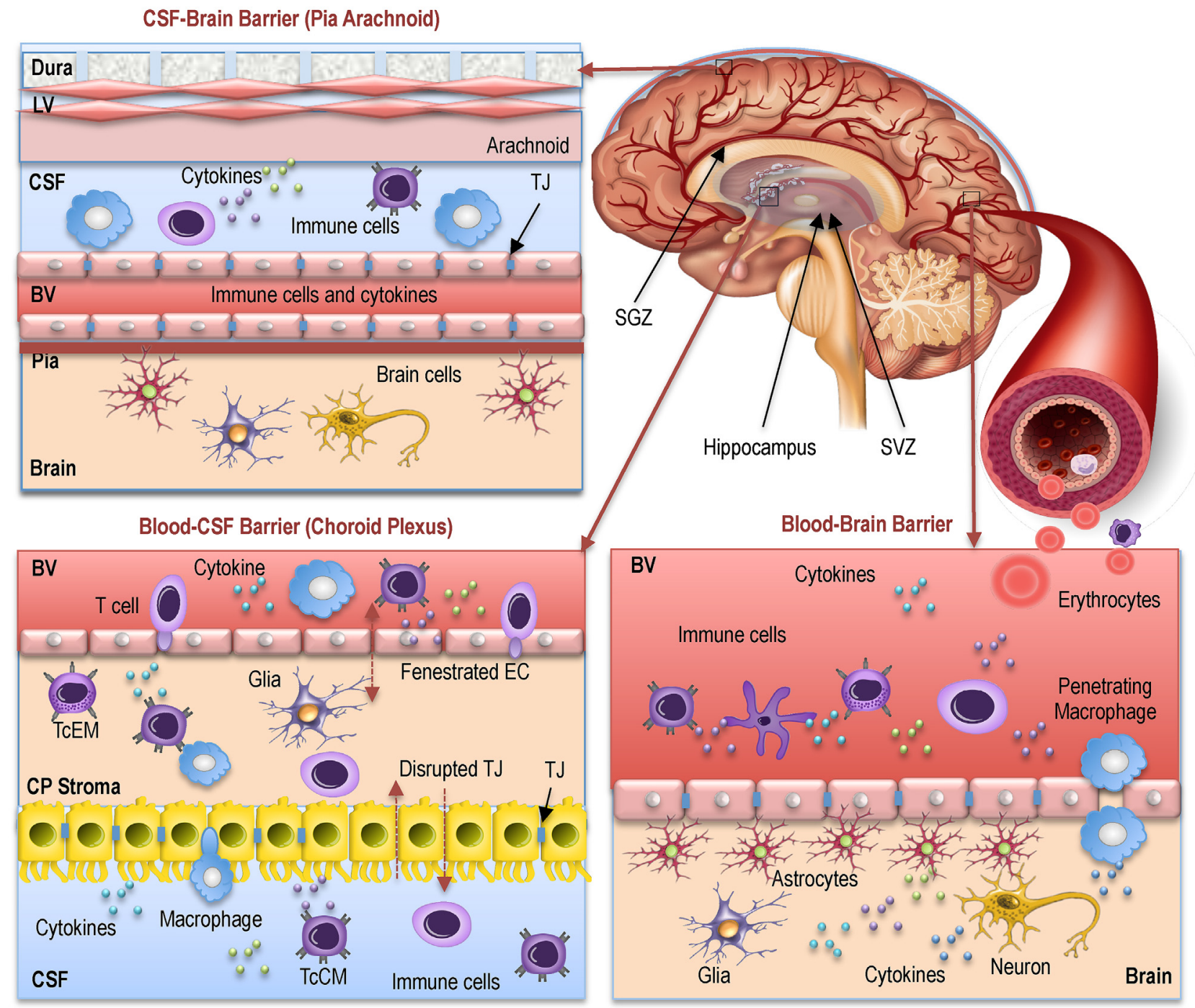

Fig. 2. Protective and dynamic barriers of the brain.

Schematic depiction of the three main barriers of the brain:

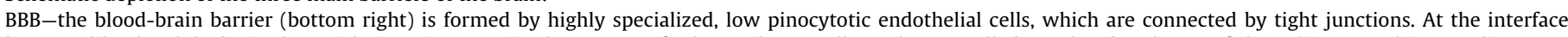

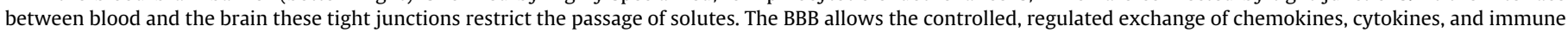
cells between the CNS and the blood as well as the secretion of immunomodulatory molecules by the BBB itself.

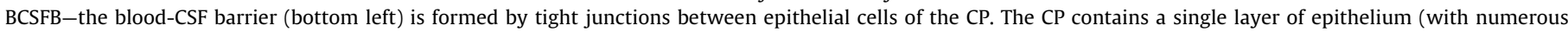

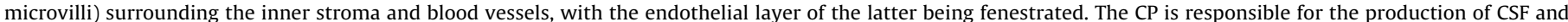

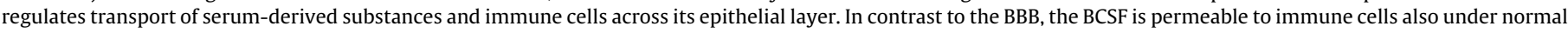
conditions, allowing immunosurveillance.

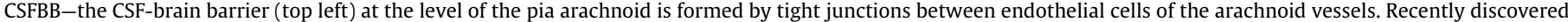
lymphatic vessels (LV) drain macromolecules and immune cells from the meninges and the CSF.

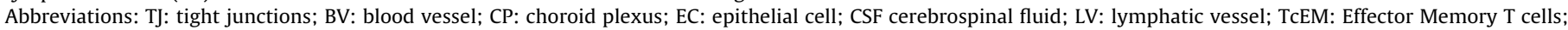
TcCM: Central Memory T cells; SVZ: subventricular zone; SGZ: subgranular zone.

cations for increased low-grade chronic inflammation and for the development of age-related diseases (Hearps et al., 2012). Thus, macrophage activation, together with inflammatory monocytes contribute to the subclinical chronic inflammatory process dubbed "inflammaging" (Franceschi et al., 2000; Franceschi et al., 2007).

The most marked changes in adaptive immunity are decreased numbers of peripheral naïve $T$ cells and concomitant accumulation of late-stage differentiated memory T cells (Ben-Smith et al., 2008; Di Benedetto et al., 2015; Malaguarnera et al., 2010; Müller et al., 2013; Müller and Pawelec, 2015; Qi et al., 2014a,b; Vescovini et al., 2014; Wistuba-Hamprecht et al., 2015) with reduced antigen receptor repertoire diversity (Johnson et al., 2014; Naylor et al., 2005; Qi et al., 2014b; Salam et al., 2013) (Fig. 3). This phenomenon results from poorly-understood age-related impairments in the hematopoietic stem cell compartment which generates fewer Tcell precursors in adult and later life on the one hand, and thymic involution at puberty which markedly reduces the production of mature T cells from their precursors on the other hand (Arnold et al., 2011).

Life-long exposure to different pathogens is regarded as a major driving factor of the phenotypic changes in the distribution of T-cell subsets over the life course. For unclear reasons, especially a latent infection with Cytomegalovirus (CMV), but not with any other herpesviruses, with recurrent episodes of reactivation has been found to promote memory T-cell "inflation" and drive T cells to a late stage of differentiation. In aged individuals, oligoclonally-expanded $\mathrm{CD}^{+} \mathrm{T}$ cells show increased expression of late-stage differentiation 


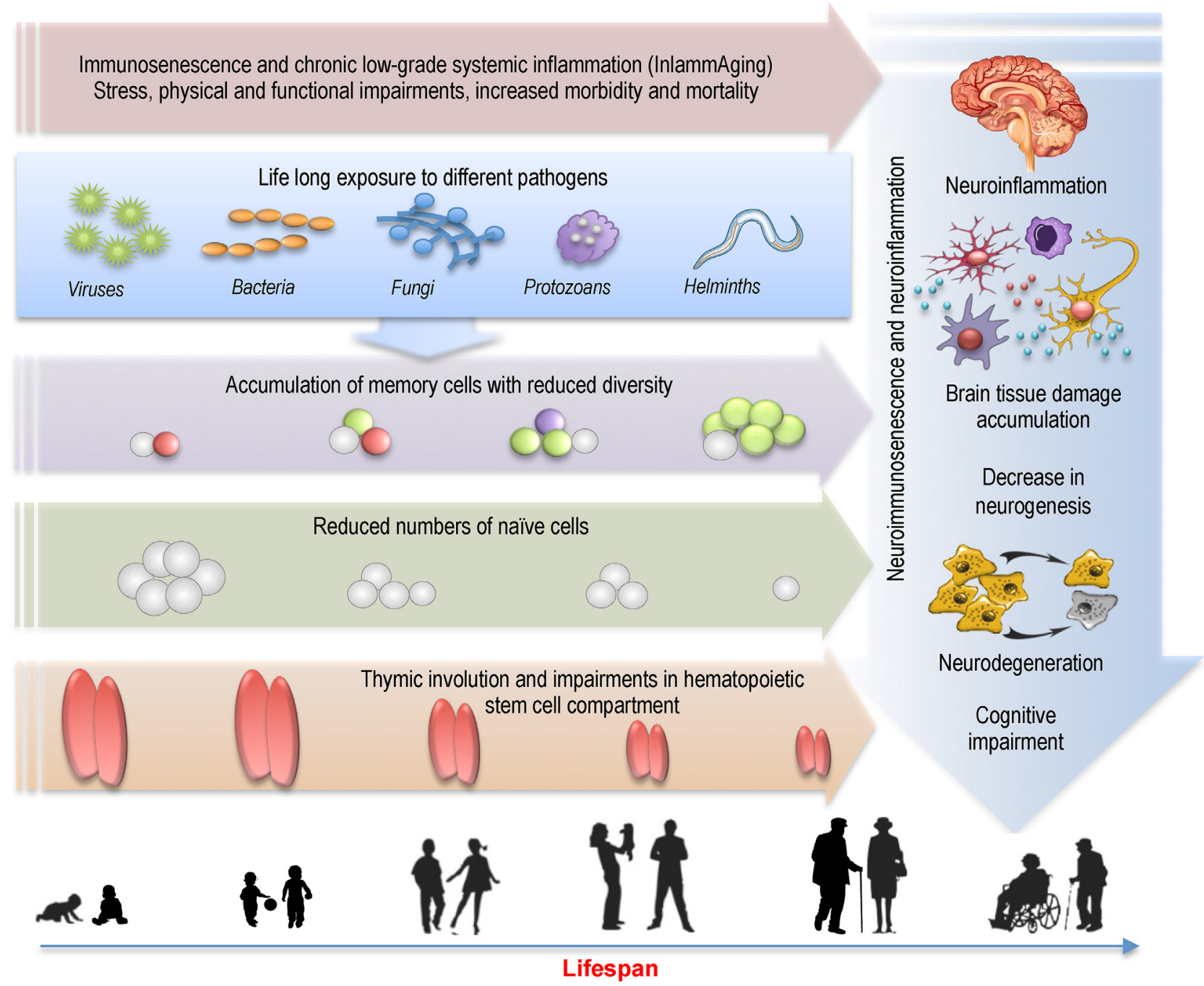

Fig. 3. Schematic representation of potential mechanisms of immunosenescence and neurosenescence.

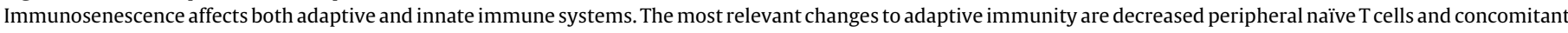

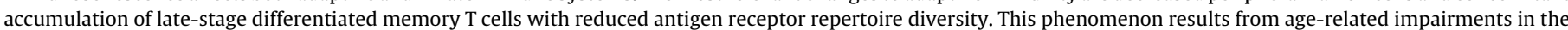

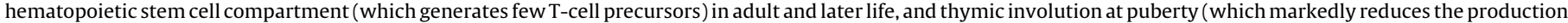

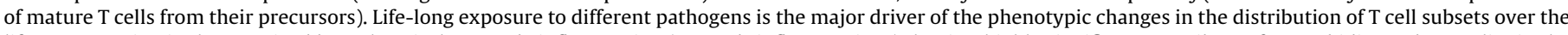

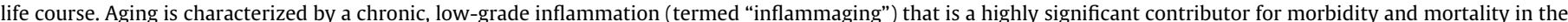

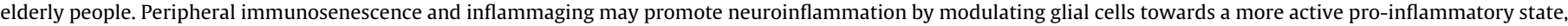

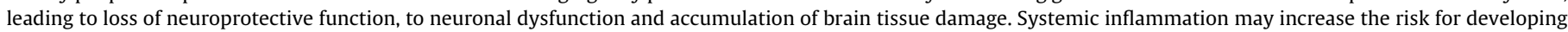
cognitive impairments and neurodegeneration.

markers. The accumulation of these highly differentiated T-cells, at least some of which may be truly senescent, contributes to the ageassociated increased production of pro-inflammatory cytokines and could thus possibly also contribute to age-related morbidity and mortality (Bennett et al., 2012; Müller et al., 2013; Pawelec and Derhovanessian, 2011; Pawelec et al., 2010).

As mentioned above, aging is characterized by a chronic, lowgrade inflammation that is probably a significant contributor to morbidity and mortality in the elderly (Franceschi et al., 2000; Franceschi and Campisi, 2014). Thus, peripheral immunosenescence and inflammaging may promote neuroinflammation by modulating glial cells towards a more active pro-inflammatory state, leading to loss of neuroprotective function, to neuronal dysfunction and accumulation of brain tissue damage (Giunta et al., 2008; von Bernhardi et al., 2010). Systemic inflammation may therefore increase the risk for developing cognitive impairment, neurological disorders and neurodegeneration (Goldeck et al., 2016; Harrison, 2016; Pizza et al., 2011). In the next section we will have a closer look at the main players contributing to the process of neuroinflammation during aging.

\section{Main immunomodulators and neuroregulators in the aging brain}

\subsection{Cytokines}

Cytokines, together with neurotransmitters and hormones, are signaling molecules possessing unique immunomodulatory functions. They can influence virtually every physiological system including neuroendocrine interactions, neurotransmitter metabolism and neuroplasticity, thereby affecting behavioral and cognitive functioning. The cytokine network, composed of the cytokines themselves, their receptors and their regulators, is present throughout the brain and other physiological systems and is highly regulated during the lifespan. Cytokines can operate within complex cascade patterns and act synergistically or antago- 
nistically. These molecules enable cross-communication between different cell types, translating environmental signals into molecular signals (Alboni and Maggi, 2015). Cytokines are normally grouped according to their effects on inflammation, as some are considered likely to increase inflammation, especially IL-1, IL-6 and TNF, whereas others (IL-4, IL-10, TGF- $\beta$ ) tend to decrease it (Ownby, 2010). It is well-established that peripherally-produced cytokines can access the brain and thus affect CNS functions via several routes. Bidirectional transport of different cytokines, including IL-1, has been demonstrated (Khairova et al., 2009). Thus, the presence of IL-1 in CSF is not only a result of local synthesis by brain cells, but is also dependent on the concentration of IL-1 in the peripheral blood. Recent work by Scheinert and colleagues demonstrated that cytokine levels change across the lifespan and vary by cognitive status, at least in rats, suggesting that serum inflammatory biomarkers are predictive of cognitive decline (Scheinert et al., 2015).

\subsection{Immune cells}

T cells (Fig. 4B) are activated by antigen-presenting cells, which are specialized to capture, process and present antigens for recognition by these cells. This can occur either in the periphery or in the CSF of the choroid plexus. Depending on the pattern of cytokine secretion, the functions of $\mathrm{T}$ cells, and the molecules that drive their differentiation, different T-helper cell phenotypes are identified. Th1 cells secrete pro-inflammatory cytokines such as IFN- $\gamma$ or TNF. Th2 cells have an anti-inflammatory function by producing IL-4 and IL-10 (Aloisi et al., 2000; Gemechu and Bentivoglio, 2012).

In addition to CNS-specific $\mathrm{CD}^{+} \mathrm{T}$ cells, which appear to be neuroprotective (Derecki et al., 2010; Kipnis et al., 2012), a novel population of $\mathrm{CD}^{+} \mathrm{T}$ cells has been reported in several regions of the brain, including the meninges and choroid plexus. These agingrelated $\mathrm{T}$ cells had effector memory and tissue-resident phenotypes and were shown to modulate microglia (Ritzel et al., 2016). The principal function of regulatory T cells in this context is to prevent or to counteract excessive CNS inflammation by release of antiinflammatory cytokines such as IL-10 or TGF- $\beta$ (Xie et al., 2015).

Bone marrow-derived monocytes (Fig. $4 \mathrm{C}$ ) reside in the perivascular space, choroid plexus and meninges of the brain, and are also able to differentiate into macrophages or dendritic cells (Auffray et al., 2007; Auffray et al., 2009). Macrophages scan the brain for pathogens and present antigens to T cells (Prinz et al., 2011). They exhibit different states of activation depending on the cytokine milieu to which they are exposed. Increased levels of IL-6 drive their differentiation into inflammatory M1-phenotype, while IL-4 exposure induces differentiation to anti-inflammatory M2-macrophages.

In addition to cytokine production, immune cells (predominantly T cells) can produce and respond to neurotransmitters such as acetylcholine, glutamate, dopamine, and serotonin. Dopamine and acetylcholine are immunostimulating neurotransmitters, whereas epinephrine and serotonin induce immunosuppression (Plata-Salaman, 1991). Moreover, these neurotransmitters are essential for modulating learning, memory and LTP. They affect not only neurons but also regulate the production and secretion of inflammatory factors from astrocytes and microglia (Leiter et al., 2016).

\subsection{Microglia and astrocytes}

Microglia are macrophage-like immune cells of the CNS involved in numerous physiological and pathological brain functions. They actively support brain development and plasticity through release of neurotransmitters and neurotrophic factors or through the pruning of synaptic elements (Deleidi et al., 2015). Given the functional significance of glial cells in the brain, it was suggested that they might represent a third element of the synapse (in addition to pre- and post-synaptic neurons), with the potential to influence synaptic transmission and in particular synaptic plasticity processes (Di Filippo et al., 2013). Therefore, the function of microglia and astrocytes is different in different states of their activation (Fig. 4A). Under baseline conditions, they are relatively quiescent and can be found in a resting state characterized by a ramified morphology with many processes, which constantly survey the surrounding area (Nimmerjahn et al., 2005). Under such resting conditions microglia carry out their essential functions of phagocytosis and clearance of debris, neuronal support as well as synaptic monitoring and remodeling (Da Mesquita et al., 2016). Following activation, both microglia and astrocytes change their shape, become amoeboid and undergo phenotypic polarization. Their activation phenotype is largely dependent on the levels of specific cytokines (Hefendehl et al., 2014; Jones and Lynch, 2015; Norden et al., 2015; Patterson, 2015).

In addition to these main phenotypes, a new "dark" microglial phenotype has been described (Bisht et al., 2016; Tay et al., 2016) that exhibits condensed cytoplasm, giving those microglia a dark appearance. Dark microglia could represent a subset of stressed, hyperactive microglia, which might be implicated in the loss of synapses (Bisht et al., 2016).

Astrocytes are closely associated with neuronal synapses and have similar neuroprotective functions as microglia in the normal brain but can also display neurotoxic effects, which depend on the cytokine milieu causing neuroinflammation (Singhal et al., 2014). It has also been demonstrated that astrocytes and the environment in the CNS have the capacity to regulate T-cell characteristics (Beurel et al., 2014), mediating inflammation and immune reactivity in the brain.

\subsection{BDNF and IGF-1}

It is now widely accepted that neurotrophic factors, such as BDNF and IGF-1, are crucial mediators of neuronal plasticity, because they are abundant in the regions particularly relevant for plasticity, where they participate in the axonal and dendritic growth and their remodeling. They are responsible for the production of neurotransmitters, for proper formation of synapses and for their functioning (Bramham and Messaoudi, 2005; Lu et al., 2005).

It could be suggested that an exaggerated brain inflammatory response, occurring during aging and/or a secondary immune challenge, may degrade the ability to provide the BDNF needed for memory-related plasticity processes at hippocampal synapses (Patterson, 2015). Many studies have shown that inflammation detrimentally affects the expression of BDNF within the brain (Guan and Fang, 2006; Schnydrig et al., 2007). The effect of a peripheral immune challenge on different BDNF transcripts has also been demonstrated (Aid et al., 2007; Chapman et al., 2012), indicating that inflammation may affect specific isoforms of this neurotrophin. It was hypothesized that one of the mechanisms by which inflammation may affect brain function could involve BDNF modulation (Calabrese et al., 2014).

IGF-1 is another important neurotrophic factor. Deficiency of this mediator has been reported to influence the development of cognitive impairment and dementia in older adults. A growing body of evidence indicates that synaptic function decreases with age and that IGF-1 contributes to this diminished information processing in the brain (Deak and Sonntag, 2012). Therefore, low levels of IGF1 are associated with worse cognitive function in elderly persons. Interestingly, results of a recent study found an optimal level of IGF1 for optimal cognitive functioning suggesting that both high and low levels of IGF-1 may be associated with poor cognition (Tumati et al., 2016). 


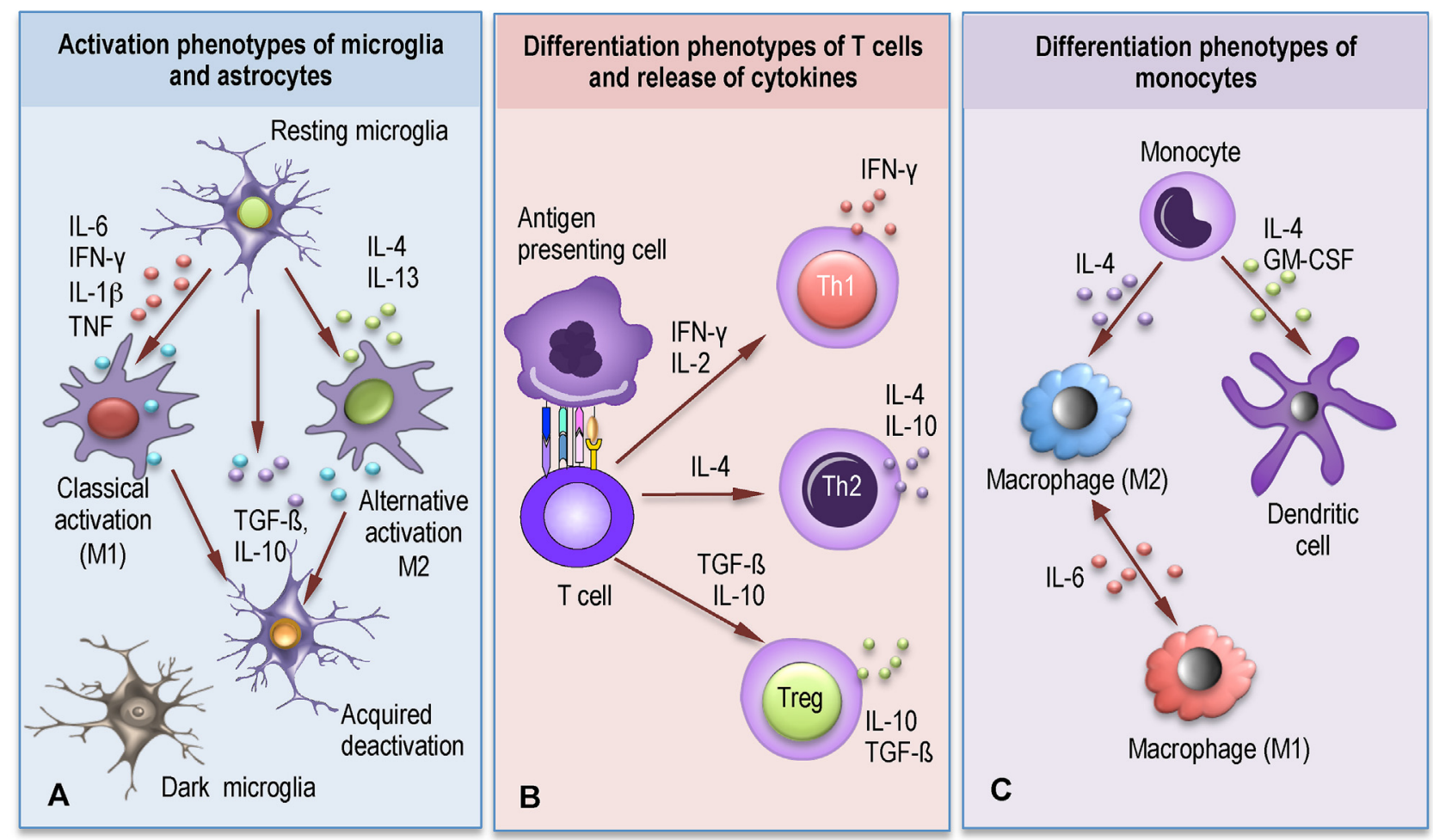

Fig. 4. Overview of the main players in brain homeostasis and neuroinflammation.

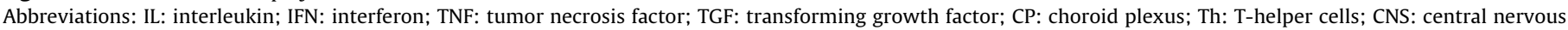
system; DC: dendritic cell.

\section{The aging brain and neuroinflammation}

Cognitive aging is characterized by an impairment of cognitive abilities. Although no agreement exists on the basic underlying mechanisms involved in this process, neuroinflammation appears to be the main contributor that links many factors associated with cognitive aging together (Ownby, 2010). As we age, we experience greater susceptibility to memory impairments following an immune challenge that is characterized by increased and prolonged production of pro-inflammatory cytokines in the otherwise healthy aged brain (Barrientos et al., 2015). It is widely established that both aging and stress can affect the neuroendocrine system, activate the hypothalamic-pituitary-adrenal (HPA) axis to release corticotropin-releasing hormone $(\mathrm{CRH})$ from the paraventricular nucleus of the hypothalamus and cause the anterior pituitary gland to secrete adrenocorticotropin (ACTH) (Fig. 5, top right). This, in turn, induces the release of glucocorticoids from the adrenal gland into the circulation (Barrientos et al., 2012). Cortisol affects the immune system in different ways: by regulating the expression of cytokines (Capoccia et al., 2013), chemokines and adhesion molecules, and by affecting immune cell migration, maturation and differentiation (Barrientos et al., 2015; Hansel et al., 2010). High levels of cortisol can negatively influence hippocampal neurogenesis directly or indirectly through regulation of expression of cytokines and their receptors on brain and immune cells. It appears that CNS levels of certain cytokines and their modulators increase as a function of age, at least in rodents (Barrientos et al., 2012; Scheinert et al., 2015; Ye and Johnson, 1999) and that aging microglia develop an altered profile characterized by an increased inflammatory state (Norden et al., 2015). Norden and colleagues referred to this as a primed profile and defined it by (i) increased baseline expression of inflammatory markers and mediators; (ii) a decreased threshold "to be activated and to switch" to a pro-inflammatory state; and (iii) exaggerated inflammatory response following immune activation (Norden et al., 2015).

Recent ultrastructural analyses have uncovered a new player in the age-related remodeling of neuronal circuits, especially at the synapse level, that is rare under homeostatic conditions, but becomes abundant during aging, neurodegeneration and chronic stress (Bisht et al., 2016). These hyperactive so-called "dark microglia" frequently reach into synaptic clefts with their highly ramified and thin processes, extensively encircle axon terminals and dendritic spines and engulf them (Bisht et al., 2016; Tay et al., 2016). Aging and neurodegeneration are exactly characterized by dysregulated interactions with synapses, resulting in neuronal loss, which in turn represents the best pathological correlate of cognitive decline (Tay et al., 2016). These conditions can sensitize the aged brain to produce an exaggerated response following exposure to a stressor or to the presence of an immune stimulus in the periphery (Sparkman and Johnson, 2008). Altered microglia profiles together with impairments in key regulatory systems can lead to prolonged neuroinflammation and age-related neurobehavioral complications (Norden et al., 2015).

On the systemic level, peripheral immunosenescence and inflammaging lead to age-related changes in the blood (Fig. 5, left). Chronic exposure to inflammatory mediators may disrupt the endothelial barrier and allow the transfer of immune cells and numerous pro-inflammatory cytokines into the brain parenchyma that, in turn, can modulate microglial phenotype and reactivity and drive low-grade brain inflammation. Brain cells, such as microglia, astrocytes, and neurons but also peripheral immune cells, such as T cells, monocytes, and macrophages participate in inflammation (Fig. 5, central). This induces an inflammatory milieu that is populated by all these resident and additional infiltrating immune cells, which participate in a complex interplay between secreted inflammatory modulators and activated cell surface receptors, such 


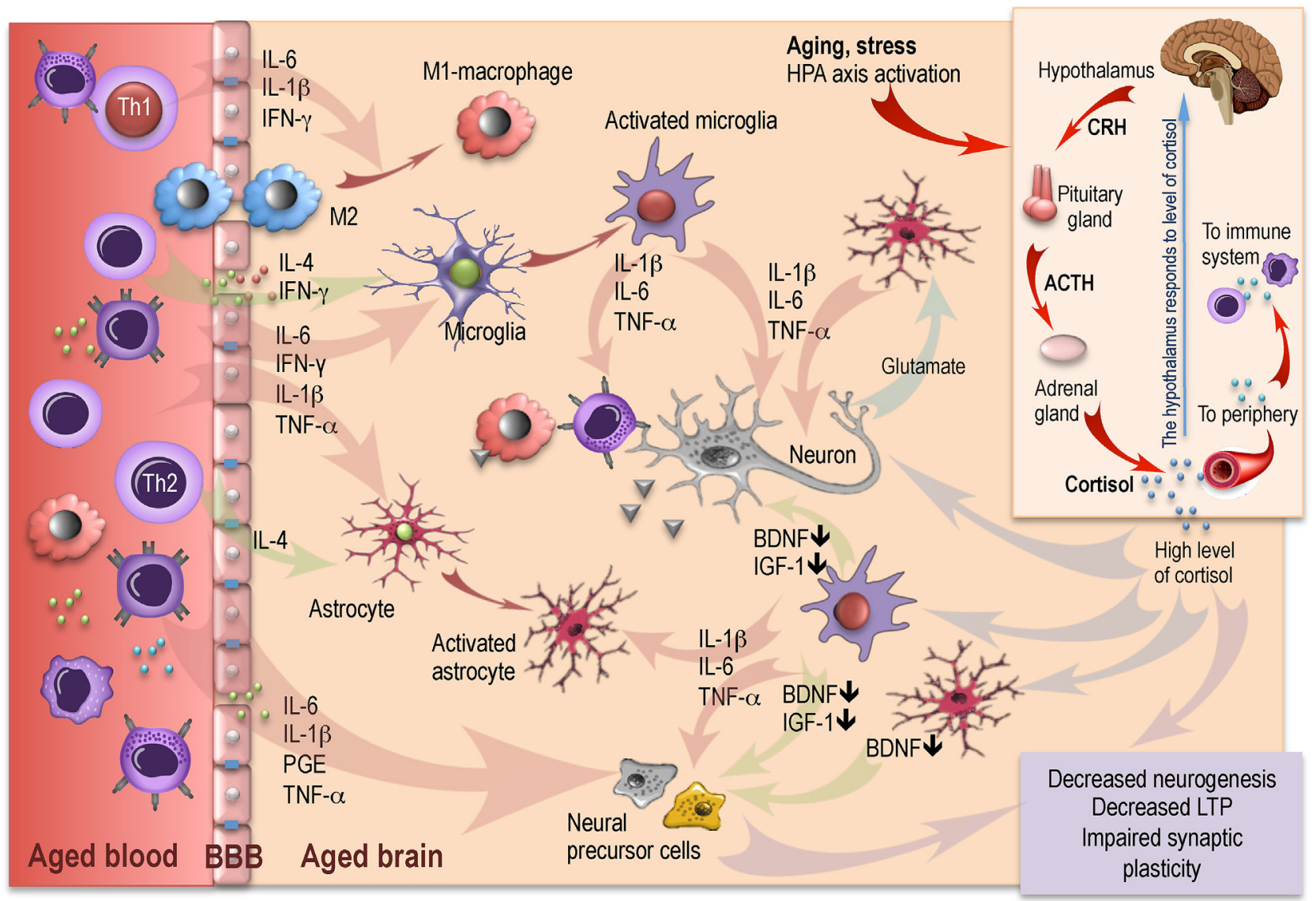

Fig. 5. Aging brain and neuroinflammation.

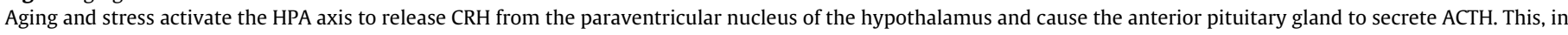

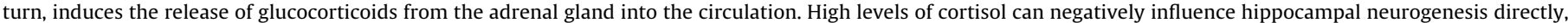

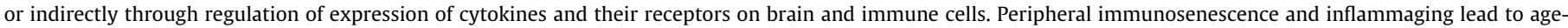

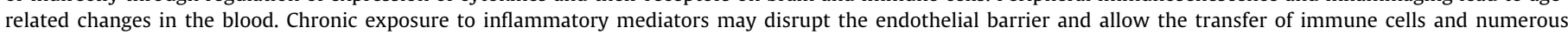

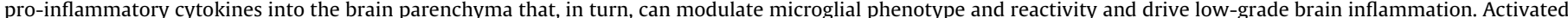

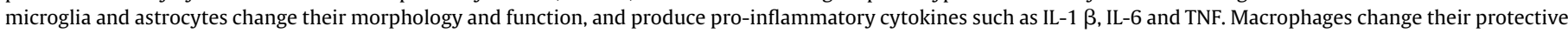

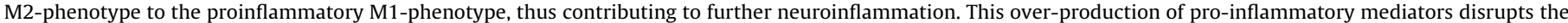

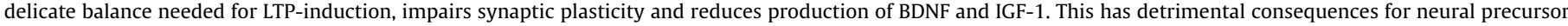
cells (decrease of neurogenesis), as well as for the normal neuronal functioning.

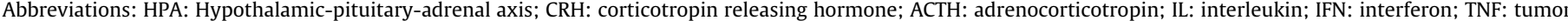
necrosis factor; LTP: long term memory potentiation; BDNF: brain-derived neurotrophic factor; IGF: insulin-like growth factor.

as toll-like receptors. These receptors are primarily expressed on cells that play central roles in the inflammatory response, including macrophages and microglia (Doty et al., 2015).

Activated microglia and astrocytes change their morphology and function, and produce pro-inflammatory cytokines such as IL$1 \beta$, IL- 6 and TNF. Recent work suggests that microglia undergo a process of senescence, similar to the one in peripheral immune cells. Senescent and hyperactive microglia have been detected in the aged and diseased brain (Deleidi et al., 2015). The aging brain in turn is apparently able to modulate the immune system and to support recruitment of immune cells from the periphery, thereby contributing further to immunosenescence and neuroinflammation (Gemechu and Bentivoglio, 2012). In addition, macrophages change their protective M2-phenotype to the pro-inflammatory M1-phenotype, thus contributing to further neuroinflammation. As the aged brain is already "primed" to respond to inflammatory stimuli, additional stress or infection may induce more detrimental changes in cognitive functioning of aged individuals (Campbell, 2004; Sparkman and Johnson, 2008). Furthermore, the age-related concurrent reduction of anti-inflammatory molecules also contributes to a sensitization to extrinsic and intrinsic stressors. T cells produce less IL- 4 and IL-10, and more IFN- $\gamma$, thereby promoting microglial activation. This has detrimental consequences for neural precursor cells leading to a decrease of neurogenesis, as well as increased decrements in learning and memory (Chen et al., 2016; Leza et al., 2015).

Taken together, even neurologically-intact aged individuals show a progressive increase in neuroinflammation characterized by increased glial activation, elevated steady-state levels of inflammatory cytokines and decreased production of anti-inflammatory molecules. This over-production of pro-inflammatory mediators disrupts the delicate balance needed for LTP-induction, reduces production of brain plasticity-related molecules, such as BDNF and IGF-1 and impairs synaptic plasticity.

\section{Impact of physical and cognitive interventions}

With increasing age, even healthy and able individuals experience some decline of cognitive performance. Investigating the nature of cognitive changes in normal aging, and the possibilities of how an enriched and stimulating lifestyle in aging could impede this decline, attracts wide scientific and social interest. Physical activity is one of the most promising and relatively simple behavioral interventions that may prevent or at least delay cognitive 

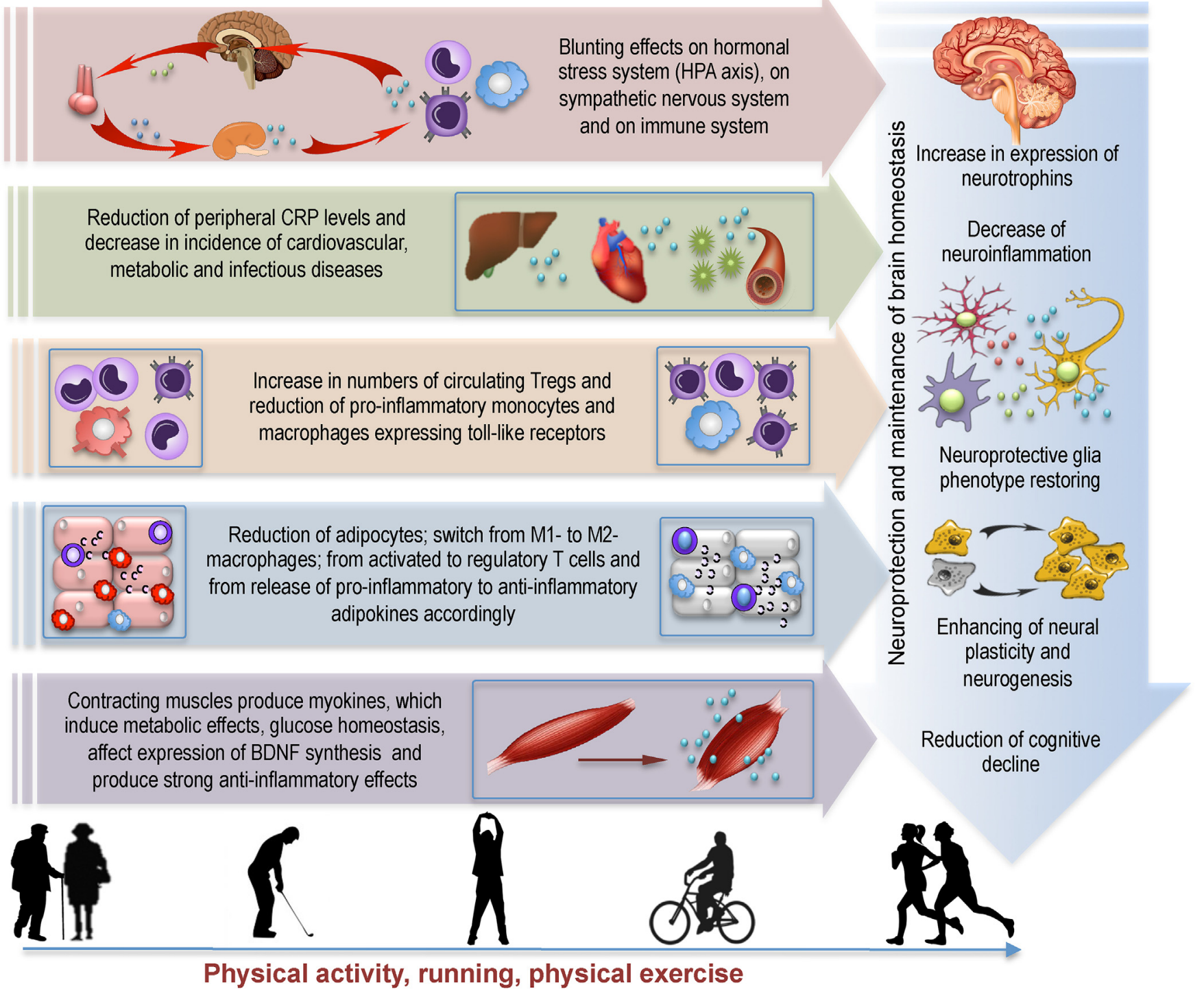

Fig. 6. Overview of the potential effects of physical activity on neuroimmunosenescence.

Abbreviations: HPA: Hypothalamic-pituitary-adrenal axis.

decline. It has been reported that physical exercises slow down cognitive impairment and maintain the volume of the hippocampus (Ahlskog et al., 2011; Colcombe and Kramer, 2003; Cotman and Berchtold, 2002; Erickson et al., 2011; Maass et al., 2015). Results from both animal (Speisman et al., 2013a; Speisman et al., 2013b) and human studies demonstrate that physical activity plays an important role in altering metabolic, structural, and functional networks of the brain and possibly in protecting from cognitive impairments in aged adults (Kim et al., 2010; Kirk-Sanchez and McGough, 2014; Snigdha et al., 2014). Promising evidence from recent animal models indicates that physical activity and the exposure to enriched environments show beneficial effects on physiological markers of brain aging, such as LTP, long-term depression (LTD), and cell excitability and can improve cognitive performance (Kumar et al., 2012). Beneficial effects of physical exercise on structural and neurochemical measures within brain regions has been shown in human too, both in younger and older adulthood (Düzel et al., 2016). Observational studies continue to suggest that adults who engage in physical activity reduce their risk of cognitive decline and dementia (Dik et al., 2003; Ferencz et al., 2014; Podewils et al., 2005; Yaffe et al., 2001). Physical inactivity is a significant risk factor for cognitive decline in aging and

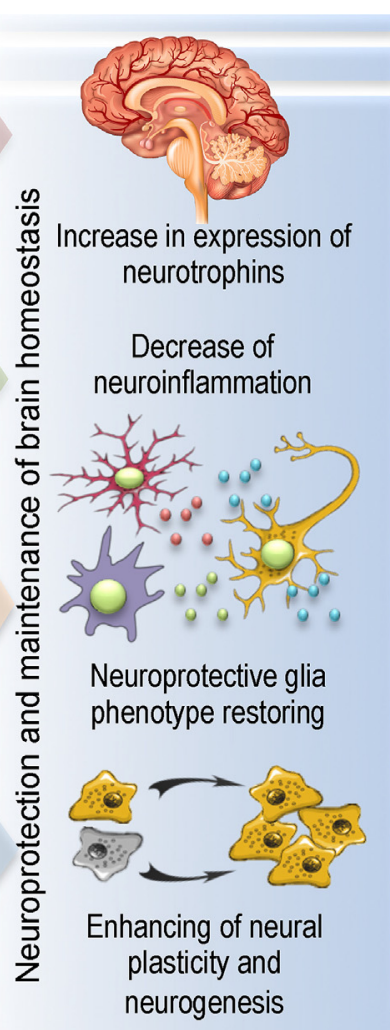

Reduction of cognitive ecline for Alzheimer's Disease (Norton et al., 2014), and exercise can exert a protective effect (Ahlskog et al., 2011; Geda et al., 2012; Ngandu et al., 2015; Prakash et al., 2015; Wirth et al., 2014), even if initiated in later life (Tolppanen et al., 2015). Physical exercise and physical activity in later life might target modifiable risk factors of aging and induce neuroprotective mechanisms (Fig. 6) (Carvalho et al., 2014; Kirk-Sanchez and McGough, 2014).

Although the exact mechanisms through which physical exercise affects cognition are not yet fully understood, there is growing evidence that selected aspects of cognition are responsive to increases in physical exercise (Colcombe and Kramer, 2003; Cotman and Berchtold, 2002; Erickson et al., 2011; Maass et al., 2015). Numerous studies have revealed anti-inflammatory and anti-oxidative effects following physical activity, which potentially exert beneficial effects on neuroplasticity, affect the expression of neurotrophins and therefore normal neuronal functions (Moylan et al., 2013). Barrientos and colleagues observed an inhibition of neuroinflammation (caused by infection) in rats performing exercises, and increased induction of BDNF mRNA in the brain of otherwise sedentary animals (Barrientos et al., 2011). Further studies with aged mice revealed that wheel running inhibits the pro-inflammatory state of microglia and their ability to proliferate, 
thus inducing a pro-neurogenic phenotype (Kohman et al., 2012). The findings by Speisman and colleagues demonstrated that daily exercises may have protective effects on cognition by modulating immune and neuroimmune cytokines and neurogenesis (Speisman et al., 2013a) in aged rats. In another recent study it was shown that an intensive training program inhibited pro-inflammatory responses in hippocampus (such as gene expression level and protein content of IL-1 $\beta$ cytokine), thereby inducing neuroprotection (Chennaoui et al., 2015).

Certainly, the anti-inflammatory effects of exercise are mediated through multidirectional pathways. Some of them are exerted on adipose tissue, skeletal muscles, immune system cells, and the cardiovascular system (Fig. 6). These effects include modulation of anti-inflammatory and pro-inflammatory cytokine profiles, redox-sensitive transcription factors, anti-oxidant and pro-oxidant enzymes, and repair proteins (Majka et al., 2009). Regular physical activity can reduce the size of adipocytes and attenuate inflammation in adipose tissue by phenotype switching from proinflammatory M1- to anti-inflammatory M2-type macrophages (Fig. 6). In addition, a reduction in the numbers of circulating pro-inflammatory type monocytes and an increase in numbers of regulatory $\mathrm{T}$ cells were found in the peripheral blood of individuals following physical activity (Pedersen, 2011; Timmerman et al., 2008).

Recent evidence suggests that contracting muscles release myokines (Dishman et al., 2006; Minter et al., 2016; Müller and Pawelec, 2014; Pedersen and Hoffman-Goetz, 2000; Petersen and Pedersen, 2005; Phillips et al., 2014), which affect the synthesis of BDNF in the dentate gyrus of the hippocampus (Phillips et al., 2014). A recent meta-analysis based on 29 studies estimated the strength of association between exercise and increased BDNF levels in humans across multiple exercise paradigms. Effect size analysis supported the role of exercise as a successful strategy to enhance BDNF activity in humans. Interestingly, the magnitude of these effects was lower in females than males (Szuhany et al., 2015). In general, differences between the sexes over the course of aging have been repeatedly reported in both animal and human studies (Beery and Zucker, 2011; Laws et al., 2016; Zagni et al., 2016). Estrogens, which are known to have inhibitory effects on neuroinflammation (in particular on microglia) appear to contribute to such sexual dimorphism (Au et al., 2016; Vegeto et al., 2008). Fluctuations in estrogen levels might alter the anti-inflammatory activity of this hormone and impair the neuronal protection.

Accumulating knowledge from clinical and pre-clinical data about the effects of physical exercise on brain function suggests that exercise may reduce inflammation and oxidative stress through a number of cellular and humoral neuroimmune changes. Astrocytes, microglia, endothelial cells of cerebrovasculature and $\mathrm{T}$ cells are known to have anti-inflammatory and neuroprotective functions via a variety of mechanisms. It is still a matter of investigation whether exercise has effects on specific neuroimmune markers, such as markers of immunosenescence (Beurel et al., 2014; Eyre and Baune, 2012; Moylan et al., 2013). Numerous studies do nevertheless suggest that regular physical activity is likely to be associated with maintenance of the more "youthful" phenotype of the immune system (Simpson, 2016; Turner, 2016).

The beneficial effects of physical fitness on mental and physical health involve protection against potentially adverse behavioral and metabolic consequences of stressful events and aging. Physical activity may have a buffering role on the hormonal stress responsive systems (Fig. 6), such as the HPA axis and the sympathetic nervous system (Simpson, 2016). Regular physical activity may also lead to a reduction of excessive inflammation and may therefore contribute to positive psycho-physiological effects. Furthermore, regular exercise may be beneficial for the brain by enriching growth factor expression and neural plasticity, thereby contributing to improved mood and cognition (Silverman and Deuster, 2014). Papenberg and colleagues investigated the impact of an inactive lifestyle and high levels of peripheral inflammatory cytokines on gray-matter volumes in a population-based study of older adults. Results showed that inflammation exacerbated negative effects on brain and cognition, and this was particularly pronounced in inactive older adults (Papenberg et al., 2016). Exercise and physical activity have been shown to improve overall health and wellbeing in aged individuals and their beneficial effects appear to impact all physiological systems (Simpson, 2016). Nonetheless, the majority of aged individuals does not implement exercise programs on a regular, extended basis. Varma and colleagues have recently demonstrated that even low-intensity but regular exercise such as daily walking was associated with greater hippocampal volume in older women (Varma et al., 2015). Epidemiological evidence and other results suggest that physical activity may be associated with improved cerebral blood flow and neuronal connectivity (Burdette et al., 2010), favorable changes in brain volume (Colcombe et al., 2006; Erickson et al., 2014), neurotrophic factors (Leckie et al., 2014), neurogenesis (Yau et al., 2011), and lower rates of cognitive decline. But some results on beneficial effects of exercise training remain still controversial. The effects of exercise may vary greatly depending on the individual's characteristics, as well as on type, intensity, frequency, and duration of exercise. Thus, it appears to be essential to develop personalized exercise programs in interventional designs (Majka et al., 2009).

Results from cognitive training programs have also been shown to result in improvements in cognitive abilities in older adults compared to control groups (Engvig et al., 2010; Schmiedek et al., 2010) and the effects were partly maintained up to five years after the intervention (Willis et al., 2006). Thus, increased mental activity in older people through directed cognitive training may represent an effective intervention to counteract cognitive decline and potentially even postpone the rise of dementia (Cheng et al., 2012).

It has been proposed that physical and cognitive exercise might interact synergistically, thereby inducing larger beneficial effects (Bamidis et al., 2014; Hotting and Roder, 2013; Kempermann et al., 2010; Kraft, 2012; Lustig et al., 2009). Several intervention studies are in line with this hypothesis demonstrating larger benefits on cognitive test performance for combined physical and cognitive activities than for either activity alone. Those studies comprise observational cross-sectional (Eskes et al., 2010), longitudinal (Karp et al., 2006), as well as controlled interventional designs (Fabre et al., 2002; Oswald et al., 2006). Results of studies with patients at risk of cognitive decline suggest that cognitive and physical exercise training represent promising non-pharmaceutical tools for improving cognition in elderly at-risk individuals (Bherer, 2015; Fiatarone Singh et al., 2014).

What might be the advantage of combined physical and cognitive exercise? Physical activity could be boosting the potential for adult neurogenesis while cognitive stimulation is increasing the recruitment of cells in an enriched environment (Kempermann et al., 2010). From an evolutionary perspective, physical and cognitive challenges have always appeared in a highly interlinked fashion (Kempermann et al., 2010). It might be assumed that the neurobiological mechanisms triggered by physical and cognitive exercise cooperate to induce plastic changes and to increase the potential for neurogenesis and synaptogenesis (Fissler et al., 2013). In other words, physical exercise may (through mitigating neuroinflammation) induce an appropriate neuroprotective environment and prepare the brain to respond to cognitive stimulation. Cognitive training then induces neuronal changes in specific networks associated with the trained skill.

Taken together, accumulating and promising evidence suggests that plastic changes are less pronounced but possible in old age, 
and might be boosted by combining both physical and cognitive activities.

\section{Concluding remarks}

Around the world, and especially in many European countries, the older segment of the adult population is growing in size and proportion (Vaupel et al., 2003). Given recent major advances in prophylaxis and medical care for cardiovascular disease and cancer, the most important societal, public health and personal challenges in dealing with demographic change will relate to cognitive function and finally, neurodegeneration. What people make out of the added years of their lives will be the most important aspect, but will only be advantageous to the individual and to society at large if people can remain active participants in daily life and work. Maintaining cognitive function will be paramount, but cognitive performance is known to decrease with increasing age, even in overtly healthy individuals. Preventing, attenuating and delaying cognitive decline is probably the most effective measure for postponing the point of time at which individuals are no longer able to lead an independent life. Effective pharmacological treatments for cognitive decline remain unavailable. Some modifiable lifestyle factors, such as poor diet and physical and cognitive inactivity have been identified as associated with increased risk of cognitive decline over the normal aging process, as opposed to overt pathological conditions (Lindenberger, 2014). Encouragingly, exercise can have a protective effect, even if initiated in advanced old age (Tolppanen et al., 2015). In this review we have described potential basic underlying processes of age-related decline, namely a progressive increase in neuroinflammation characterized by increased glial activation, elevated steady-state levels of inflammatory cytokines and decreased production of neurotrophic molecules, as well as possible positive effects of physical exercise and cognitive interventions. It is our hypothesis, as partly summarized here, that a judicious combination of exercise and dietary interventions, cognitive training, pharmacological manipulation of immunosenescence and inflammatory processes will eventually deliver an optimal individualized regime for the maintenance of the best possible cognitive function over the lifespan of every individual.

\section{Conflict of interest}

The authors have no conflicting financial interests to declare.

\section{Acknowledgement}

This research was supported by the Max Planck Society, and the Croeni Foundation (to GP)

\section{References}

Ahlskog, J.E., Geda, Y.E., Graff-Radford, N.R., Petersen, R.C., 2011. Physical exercise as a preventive or disease-modifying treatment of dementia and brain aging. Mayo Clin. Proc. 86, 876-884.

Aid, T., Kazantseva, A., Piirsoo, M., Palm, K., Timmusk, T., 2007. Mouse and rat BDNF gene structure and expression revisited. J. Neurosci. Res. 85, 525-535.

Aimone, J.B., Li, Y., Lee, S.W., Clemenson, G.D., Deng, W., Gage, F.H., 2014. Regulation and function of adult neurogenesis: from genes to cognition. Physiol. Rev. 94, 991-1026.

Alboni, S., Maggi, L., 2015. Editorial: cytokines as players of neuronal plasticity and sensitivity to environment in healthy and pathological brain. Front. Cell. Neurosci. 9, 508

Aloisi, F., Ria, F., Adorini, L., 2000. Regulation of T-cell responses by CNS antigen-presenting cells: different roles for microglia and astrocytes. Immunol. Today $21,141-147$
Anthony, D.C., Bolton, S.J., Fearn, S., Perry, V.H., 1997. Age-related effects of interleukin-1 beta on polymorphonuclear neutrophil-dependent increases in blood-brain barrier permeability in rats. Brain 120 (Pt 3), 435-444.

Arnold, C.R., Wolf, J., Brunner, S., Herndler-Brandstetter, D., Grubeck-Loebenstein, B., 2011. Gain and loss of T cell subsets in old age-age-related reshaping of the T cell repertoire. J. Clin. Immunol. 31, 137-146.

Au, A., Feher, A., McPhee, L., Jessa, A., Oh, S., Einstein, G., 2016. Estrogens, inflammation and cognition. Front. Neuroendocrinol. 40, 87-100.

Auffray, C., Fogg, D., Garfa, M., Elain, G., Join-Lambert, O., Kayal, S., Sarnacki, S., Cumano, A., Lauvau, G., Geissmann, F., 2007. Monitoring of blood vessels and tissues by a population of monocytes with patrolling behavior. Science 317 , 666-670.

Auffray, C., Fogg, D.K., Narni-Mancinelli, E., Senechal, B., Trouillet, C., Saederup, N. Leemput, J., Bigot, K., Campisi, L., Abitbol, M., Molina, T., Charo, I., Hume, D.A., Cumano, A., Lauvau, G., Geissmann, F., 2009. CX3CR1+ CD115+ CD135+ common macrophage/DC precursors and the role of CX3CR1 in their response to inflammation. J. Exp. Med. 206, 595-606.

Bains, J.S., Oliet, S.H., 2007. Glia: they make your memories stick! Trends Neurosci. 30, 417-424.

Bamidis, P.D., Vivas, A.B., Styliadis, C., Frantzidis, C., Klados, M., Schlee, W., Siountas, A., Papageorgiou, S.G., 2014. A review of physical and cognitive interventions in aging. Neurosci. Biobehav. Rev. 44, 206-220.

Banks, W.A., 2015. The blood-brain barrier in neuroimmunology: tales of separation and assimilation. Brain Behav. Immun. 44, 1-8.

Barrientos, R.M., Frank, M.G., Crysdale, N.Y., Chapman, T.R., Ahrendsen, J.T., Day, H.E., Campeau, S., Watkins, L.R., Patterson, S.L., Maier, S.F., 2011. Little exercise, big effects: reversing aging and infection-induced memory deficits, and underlying processes. J. Neurosci. 31, 11578-11586.

Barrientos, R.M., Frank, M.G., Watkins, L.R., Maier, S.F., 2012. Aging-related changes in neuroimmune-endocrine function: implications for hippocampal-dependent cognition. Horm. Behav. 62, 219-227.

Barrientos, R.M., Kitt, M.M., Watkins, L.R., Maier, S.F., 2015. Neuroinflammation in the normal aging hippocampus. Neuroscience 309, 84-99.

Baruch, K., Schwartz, M., 2013. CNS-specific T cells shape brain function via the choroid plexus. Brain Behav. Immun. 34, 11-16.

Baune, B.T., Ponath, G., Rothermundt, M., Riess, O., Funke, H., Berger, K., 2008. Association between genetic variants of IL-1 beta, IL-6 and TNF-alpha cytokines and cognitive performance in the elderly general population of the MEMO-study. Psychoneuroendocrinology 33, 68-76.

Beattie, E.C., Stellwagen, D., Morishita, W., Bresnahan, J.C., Ha, B.K., Von Zastrow, M., Beattie, M.S., Malenka, R.C., 2002. Control of synaptic strength by glial TNFalpha. Science 295, 2282-2285.

Beery, A.K., Zucker, I., 2011. Sex bias in neuroscience and biomedical research. Neurosci. Biobehav. Rev. 35, 565-572.

Ben-Smith, A., Gorak-Stolinska, P., Floyd, S., Weir, R.E., Lalor, M.K., Mvula, H., Crampin, A.C., Wallace, D., Beverley, P.C., Fine, P.E., Dockrell, H.M., 2008. Differences between naive and memory T cell phenotype in Malawian and UK adolescents: a role for Cytomegalovirus? BMC Infect. Dis. 8, 139.

Bennett, J.M., Glaser, R., Malarkey, W.B., Beversdorf, D.Q., Peng, J., Kiecolt-Glaser, J.K., 2012. Inflammation and reactivation of latent herpesviruses in older adults. Brain Behav. Immun. 26, 739-746.

Berry, A., Carnevale, D., Giorgio, M., Pelicci, P.G., de Kloet, E.R., Alleva, E., Minghetti, L., Cirulli, F., 2010. Greater resistance to inflammation at adulthood could contribute to extended life span of p66(Shc-/-) mice. Exp. Gerontol. 45, 343-350.

Berry, A., Panetta, P., Luoni, A., Bellisario, V., Capoccia, S., Riva, M.A., Cirulli, F., 2015. Decreased Bdnf expression and reduced social behavior in periadolescent rats following prenatal stress. Dev. Psychobiol. 57, 365-373.

Beurel, E., Harrington, L.E., Buchser, W., Lemmon, V., Jope, R.S., 2014. Astrocytes modulate the polarization of CD4+ T cells to Th1 cells. PLoS One 9 , e86257.

Bherer, L., 2015. Cognitive plasticity in older adults: effects of cognitive training and physical exercise. Ann. N. Y. Acad. Sci. 1337, 1-6.

Bisht, K., Sharma, K.P., Lecours, C., Sanchez, M.G., El Hajj, H., Milior, G., Olmos-Alonso, A., Gomez-Nicola, D., Luheshi, G., Vallieres, L., Branchi, I., Maggi, L., Limatola, C., Butovsky, O., Tremblay, M.E., 2016. Dark microglia: a new phenotype predominantly associated with pathological states. Glia 64, $826-839$.

Bramham, C.R., Messaoudi, E., 2005. BDNF function in adult synaptic plasticity: the synaptic consolidation hypothesis. Prog. Neurobiol. 76, 99-125.

Brynskikh, A., Warren, T., Zhu, J., Kipnis, J., 2008. Adaptive immunity affects learning behavior in mice. Brain Behav. Immun. 22, 861-869.

Burch, D., 2014. What could computerized brain training learn from evidence-based medicine? PLoS Med. 11, e1001758.

Burdette, J.H., Laurienti, P.J., Espeland, M.A., Morgan, A., Telesford, Q., Vechlekar, C.D., Hayasaka, S., Jennings, J.M., Katula, J.A., Kraft, R.A., Rejeski, W.J., 2010. Using network science to evaluate exercise-associated brain changes in older adults. Front Aging Neurosci. 2, 23

Calabrese, F., Rossetti, A.C., Racagni, G., Gass, P., Riva, M.A., Molteni, R., 2014. Brain-derived neurotrophic factor: a bridge between inflammation and neuroplasticity. Front. Cell. Neurosci. 8, 430.

Campbell, A., 2004. Inflammation, neurodegenerative diseases, and environmental exposures. Ann. N. Y. Acad. Sci. 1035, 117-132.

Capoccia, S., Berry, A., Bellisario, V., Vacirca, D., Ortona, E., Alleva, E., Cirulli, F., 2013. Quality and timing of stressors differentially impact on brain plasticity and neuroendocrine-immune function in mice. Neural Plast. 2013, 971817. 
Carvalho, A., Rea, I.M., Parimon, T., Cusack, B.J., 2014. Physical activity and cognitive function in individuals over 60 years of age: a systematic review. Clin. Interv. Aging 9, 661-682.

Chapman, T.R., Barrientos, R.M., Ahrendsen, J.T., Hoover, J.M., Maier, S.F., Patterson, S.L., 2012. Aging and infection reduce expression of specific brain-derived neurotrophic factor mRNAs in hippocampus. Neurobiol. Aging 33 (83), e831-814.

Chen, W.W., Zhang, X., Huang, W.J., 2016. Role of neuroinflammation in neurodegenerative diseases (Review). Mol. Med. Rep. 13, 3391-3396.

Cheng, Y., Wu, W., Feng, W., Wang, J., Chen, Y., Shen, Y., Li, Q., Zhang, X., Li, C., 2012. The effects of multi-domain versus single-domain cognitive training in non-demented older people: a randomized controlled trial. BMC Med. 10, 30

Chennaoui, M., Gomez-Merino, D., Drogou, C., Geoffroy, H., Dispersyn, G., Langrume, C., Ciret, S., Gallopin, T., Sauvet, F., 2015. Effects of exercise on brain and peripheral inflammatory biomarkers induced by total sleep deprivation in rats. J. Inflamm. (Lond.) 12, 56

Colcombe, S., Kramer, A.F., 2003. Fitness effects on the cognitive function of older adults: a meta-analytic study. Psychol. Sci. 14, 125-130.

Colcombe, S.J., Erickson, K.I., Scalf, P.E., Kim, J.S., Prakash, R., McAuley, E., Elavsky, S., Marquez, D.X., Hu, L., Kramer, A.F., 2006. Aerobic exercise training increases brain volume in aging humans. J. Gerontol. A: Biol. Sci. Med. Sci. 61, 1166-1170.

Cotman, C.W., Berchtold, N.C., 2002. Exercise: a behavioral intervention to enhance brain health and plasticity. Trends Neurosci. 25, 295-301.

Düzel, E., van Praag, H., Sendtner, M., 2016. Can physical exercise in old age improve memory and hippocampal function? Brain 139, 662-673.

Da Mesquita, S., Ferreira, A.C., Sousa, J.C., Correia-Neves, M., Sousa, N., Marques, F. 2016. Insights on the pathophysiology of Alzheimer's disease: the crosstalk between amyloid pathology, neuroinflammation and the peripheral immune system. Neurosci. Biobehav. Rev. 68, 547-562.

Deak, F., Sonntag, W.E., 2012. Aging, synaptic dysfunction, and insulin-like growth factor (IGF)-1. J. Gerontol. A. Biol. Sci. Med. Sci. 67, 611-625

Deleidi, M., Jaggle, M., Rubino, G., 2015. Immune aging, dysmetabolism, and inflammation in neurological diseases. Front. Neurosci. 9, 172

Derecki, N.C., Cardani, A.N., Yang, C.H., Quinnies, K.M., Crihfield, A., Lynch, K.R., Kipnis, J., 2010. Regulation of learning and memory by meningeal immunity: a key role for IL-4. J. Exp. Med. 207, 1067-1080.

Di Benedetto, S., Derhovanessian, E., Steinhagen-Thiessen, E., Goldeck, D., Muller, L., Pawelec, G., 2015. Impact of age, sex and CMV-infection on peripheral T cell phenotypes: results from the Berlin BASE-II Study. Biogerontology 16 , 631-643.

Di Filippo, M., Chiasserini, D., Gardoni, F., Viviani, B., Tozzi, A., Giampa, C., Costa, C., Tantucci, M., Zianni, E., Boraso, M., Siliquini, S., de Iure, A., Ghiglieri, V., Colcelli, E., Baker, D., Sarchielli, P., Fusco, F.R., Di Luca, M., Calabresi, P., 2013. Effects of central and peripheral inflammation on hippocampal synaptic plasticity. Neurobiol. Dis. 52, 229-236.

Dik, M., Deeg, D.J., Visser, M., Jonker, C., 2003. Early life physical activity and cognition at old age. J. Clin. Exp. Neuropsychol. 25, 643-653.

Dishman, R.K., Berthoud, H.R., Booth, F.W., Cotman, C.W., Edgerton, V.R., Fleshner, M.R., Gandevia, S.C., Gomez-Pinilla, F., Greenwood, B.N., Hillman, C.H., Kramer, A.F., Levin, B.E., Moran, T.H., Russo-Neustadt, A.A., Salamone, J.D., Van Hoomissen, J.D., Wade, C.E., York, D.A., Zigmond, M.J., 2006. Neurobiology of exercise. Obesity 14, 345-356.

Doty, K.R., Guillot-Sestier, M.V., Town, T., 2015. The role of the immune system in neurodegenerative disorders: adaptive or maladaptive? Brain Res. 1617, $155-173$.

Dunn, A.J., 1992. Endotoxin-induced activation of cerebral catecholamine and serotonin metabolism: comparison with interleukin-1. J. Pharmacol. Exp. Ther. 261, 964-969.

Elenkov, I.J., Iezzoni, D.G., Daly, A., Harris, A.G., Chrousos, G.P., 2005. Cytokine dysregulation, inflammation and well-being. Neuroimmunomodulation 12 , 255-269.

Ellwardt, E., Walsh, J.T., Kipnis, J., Zipp, F., 2016. Understanding the role of T cells in CNS homeostasis. Trends Immunol. 37, 154-165.

Engelhardt, B., Carare, R.O., Bechmann, I., Flugel, A., Laman, J.D., Weller, R.O., 2016. Vascular, glial, and lymphatic immune gateways of the central nervous system. Acta Neuropathol. 132, 317-338.

Engvig, A., Fjell, A.M., Westlye, L.T., Moberget, T., Sundseth, O., Larsen, V.A., Walhovd, K.B., 2010. Effects of memory training on cortical thickness in the elderly. Neuroimage 52, 1667-1676.

Erickson, K.I., Voss, M.W., Prakash, R.S., Basak, C., Szabo, A., Chaddock, L., Kim, J.S., Heo, S., Alves, H., White, S.M., Wojcicki, T.R., Mailey, E., Vieira, V.J., Martin, S.A., Pence, B.D., Woods, J.A., McAuley, E., Kramer, A.F., 2011. Exercise training increases size of hippocampus and improves memory. Proc. Natl. Acad. Sci. U. S. A. 108, 3017-3022.

Erickson, K.I., Leckie, R.L., Weinstein, A.M., 2014. Physical activity, fitness, and gray matter volume. Neurobiol. Aging 35 (Suppl. (2)), S20-28.

Eskes, G.A., Longman, S., Brown, A.D., McMorris, C.A., Langdon, K.D., Hogan, D.B., Poulin, M., 2010. Contribution of physical fitness, cerebrovascular reserve and cognitive stimulation to cognitive function in post-menopausal women. Front Aging Neurosci. 2, 137

Eyre, H., Baune, B.T., 2012. Neuroimmunological effects of physical exercise in depression. Brain Behav. Immun. 26, 251-266.

Fabre, C., Chamari, K., Mucci, P., Masse-Biron, J., Prefaut, C., 2002. Improvement of cognitive function by mental and/or individualized aerobic training in healthy elderly subjects. Int. J. Sports Med. 23, 415-421.
Feigenson, K.A., Kusnecov, A.W., Silverstein, S.M., 2014. Inflammation and the two-hit hypothesis of schizophrenia. Neurosci. Biobehav. Rev. 38, 72-93.

Ferencz, B., Laukka, E.J., Welmer, A.K., Kalpouzos, G., Angleman, S., Keller, L., Graff, C., Lovden, M., Backman, L., 2014. The benefits of staying active in old age: physical activity counteracts the negative influence of PICALM, BIN1, and CLU risk alleles on episodic memory functioning. Psychol. Aging 29, 440-449.

Fiatarone Singh, M.A., Gates, N., Saigal, N., Wilson, G.C., Meiklejohn, J., Brodaty, H., Wen, W., Singh, N., Baune, B.T., Suo, C., Baker, M.K., Foroughi, N., Wang, Y., Sachdev, P.S., Valenzuela, M., 2014. The Study of Mental and Resistance Training (SMART) study-resistance training and/or cognitive training in mild cognitive impairment: a randomized, double-blind, double-sham controlled trial. J. Am. Med. Dir. Assoc. 15, 873-880.

Fissler, P., Kuster, O., Schlee, W., Kolassa, I.T., 2013. Novelty interventions to enhance broad cognitive abilities and prevent dementia: synergistic approaches for the facilitation of positive plastic change. Prog. Brain Res. 207, 403-434

Franceschi, C., Campisi, J., 2014. Chronic inflammation (inflammaging) and its potential contribution to age-associated diseases. J. Gerontol. A. Biol. Sci. Med. Sci. 69 (Suppl. (1)), S4-S9.

Franceschi, C., Bonafe, M., Valensin, S., Olivieri, F., De Luca, M., Ottaviani, E., De Benedictis, G., 2000. Inflamm-aging: an evolutionary perspective on immunosenescence. Ann. N. Y. Acad. Sci. 908, 244-254.

Franceschi, C., Capri, M., Monti, D., Giunta, S., Olivieri, F., Sevini, F., Panourgia, M.P. Invidia, L., Celani, L., Scurti, M., Cevenini, E., Castellani, G.C., Salvioli, S., 2007. Inflammaging and anti-inflammaging: a systemic perspective on aging and longevity emerged from studies in humans. Mech. Ageing Dev. 128, 92-105.

Geda, Y.E., Silber, T.C., Roberts, R.O., Knopman, D.S., Christianson, T.J., Pankratz, V.S., Boeve, B.F., Tangalos, E.G., Petersen, R.C., 2012. Computer activities physical exercise, aging, and mild cognitive impairment: a population-based study. Mayo Clin. Proc. 87, 437-442.

Gemechu, J.M., Bentivoglio, M., 2012. T cell recruitment in the brain during normal aging. Front. Cell. Neurosci. 6, 38.

Giunta, B., Fernandez, F., Nikolic, W.V., Obregon, D., Rrapo, E., Town, T., Tan, J., 2008. Inflammaging as a prodrome to Alzheimer's disease. J. Neuroinflammation 5, 51.

Goldeck, D., Witkowski, J.M., Fulop, T., Pawelec, G., 2016. Peripheral immune signatures in alzheimer disease. Curr. Alzheimer Res. 13, 739-749.

Goshen, I., Yirmiya, R., 2009. Interleukin-1 (IL-1): a central regulator of stress responses. Front. Neuroendocrinol. 30, 30-45.

Goshen, I., Kreisel, T., Ben-Menachem-Zidon, O., Licht, T., Weidenfeld, J., Ben-Hur, T., Yirmiya, R., 2008. Brain interleukin-1 mediates chronic stress-induced depression in mice via adrenocortical activation and hippocampal neurogenesis suppression. Mol. Psychiatry 13, 717-728.

Guan, Z., Fang, J., 2006. Peripheral immune activation by lipopolysaccharide decreases neurotrophins in the cortex and hippocampus in rats. Brain Behav. Immun. 20, 64-71.

Gutierrez, E.G., Banks, W.A., Kastin, A.J., 1993. Murine tumor necrosis factor alpha is transported from blood to brain in the mouse. J. Neuroimmunol. 47, 169-176.

Gutierrez, E.G., Banks, W.A., Kastin, A.J., 1994. Blood-borne interleukin-1 receptor antagonist crosses the blood-brain barrier. J. Neuroimmunol. 55, 153-160.

Hansel, A., Hong, S., Camara, R.J., von Kanel, R., 2010. Inflammation as a psychophysiological biomarker in chronic psychosocial stress. Neurosci. Biobehav. Rev. 35, 115-121.

Hansen, M.K., Taishi, P., Chen, Z., Krueger, J.M., 1998. Vagotomy blocks the induction of interleukin-1beta (IL-1beta) mRNA in the brain of rats in response to systemic IL-1beta. J. Neurosci. 18, 2247-2253.

Hansen, M.K., Nguyen, K.T., Goehler, L.E., Gaykema, R.P., Fleshner, M., Maier, S.F., Watkins, L.R., 2000. Effects of vagotomy on lipopolysaccharide-induced brain interleukin-1beta protein in rats. Auton. Neurosci. 85, 119-126.

Hanson, M.A., Gluckman, P.D., 2014. Early developmental conditioning of later health and disease: physiology or pathophysiology? Physiol. Rev. 94, 1027-1076

Harrison, N.A., 2016. Brain structures implicated in inflammation-associated depression. Curr. Top. Behav. Neurosci.

Hasegawa-Ishii, S., Inaba, M., Umegaki, H., Unno, K., Wakabayashi, K., Shimada, A., 2016. Endotoxemia-induced cytokine-mediated responses of hippocampal astrocytes transmitted by cells of the brain-immune interface. Sci. Rep. 6 , 25457.

Hearps, A.C., Martin, G.E., Angelovich, T.A., Cheng, W.J., Maisa, A., Landay, A.L., Jaworowski, A., Crowe, S.M., 2012. Aging is associated with chronic innate immune activation and dysregulation of monocyte phenotype and function. Aging Cell 11, 867-875.

Hefendehl, J.K., Neher, J.J., Suhs, R.B., Kohsaka, S., Skodras, A., Jucker, M., 2014. Homeostatic and injury-induced microglia behavior in the aging brain. Aging Cell 13, 60-69.

Hickey, W.F., 2000. P selectin, pioneer cells and the path to inflammation. Brain 123 (Pt 6), 1073-1074.

Holvoet, P., 2012. Stress in obesity and associated metabolic and cardiovascular disorders. Scientifica (Cairo) 2012, 205027.

Hotting, K., Roder, B., 2013. Beneficial effects of physical exercise on neuroplasticity and cognition. Neurosci. Biobehav. Rev. 37, 2243-2257.

Iozzo, P., Holmes, M., Schmidt, M.V., Cirulli, F., Guzzardi, M.A., Berry, A., Balsevich, G., Andreassi, M.G., Wesselink, J.J., Liistro, T., Gomez-Puertas, P., Eriksson, J.G., Seckl, J., 2014. Developmental ORIgins of Healthy and Unhealthy AgeiNg: the role of maternal obesity-introduction to DORIAN. Obes Facts 7, 130-151. 
Johnson, P.L., Goronzy, J.J., Antia, R., 2014. A population biological approach to understanding the maintenance and loss of the T-cell repertoire during aging. Immunology 142, 167-175.

Jones, R.S., Lynch, M.A., 2015. How dependent is synaptic plasticity on microglial phenotype? Neuropharmacology 96, 3-10.

Kempermann, G., Gast, D., Gage, F.H., 2002. Neuroplasticity in old age: sustained fivefold induction of hippocampal neurogenesis by long-term environmental enrichment. Ann. Neurol. 52, 135-143.

Kempermann, G., Fabel, K., Ehninger, D., Babu, H., Leal-Galicia, P., Garthe, A., Wolf, S.A., 2010. Why and how physical activity promotes experience-induced brain plasticity. Front. Neurosci. 4, 189.

Khairova, R.A., Machado-Vieira, R., Du, J., Manji, H.K., 2009. A potential role for pro-inflammatory cytokines in regulating synaptic plasticity in major depressive disorder. Int. J. Neuropsychopharmacol. 12, 561-578.

Kim, S.E., Ko, I.G., Kim, B.K., Shin, M.S., Cho, S., Kim, C.J., Kim, S.H., Baek, S.S., Lee, E.K., Jee, Y.S., 2010. Treadmill exercise prevents aging-induced failure of memory through an increase in neurogenesis and suppression of apoptosis in rat hippocampus. Exp. Gerontol. 45, 357-365.

Kipnis, J., Cohen, H., Cardon, M., Ziv, Y., Schwartz, M., 2004. T cell deficiency leads to cognitive dysfunction: implications for therapeutic vaccination for schizophrenia and other psychiatric conditions. Proc. Natl. Acad. Sci. U. S. A. $101,8180-8185$

Kipnis, J., Gadani, S., Derecki, N.C., 2012. Pro-cognitive properties of T cells. Nat. Rev. Immunol. 12, 663-669.

Kirk-Sanchez, N.J., McGough, E.L., 2014. Physical exercise and cognitive performance in the elderly: current perspectives. Clin. Interv. Aging 9, 51-62.

Kohman, R.A., DeYoung, E.K., Bhattacharya, T.K., Peterson, L.N., Rhodes, J.S., 2012. Wheel running attenuates microglia proliferation and increases expression of a proneurogenic phenotype in the hippocampus of aged mice. Brain Behav. Immun. 26, 803-810

Kraft, E., 2012. Cognitive function, physical activity, and aging: possible biological links and implications for multimodal interventions. Neuropsychol. Dev. Cogn. Sect. B: Aging Neuropsychol. Cogn. 19, 248-263.

Kumar, A., Rani, A., Tchigranova, O., Lee, W.H., Foster, T.C., 2012. Influence of late-life exposure to environmental enrichment or exercise on hippocampal function and CA1 senescent physiology. Neurobiol. Aging 33, e1-17.

Lövdén, M., Wenger, E., Martensson, J., Lindenberger, U., Backman, L., 2013. Structural brain plasticity in adult learning and development. Neurosci. Biobehav. Rev, 37, 2296-2310.

Laws, K.R., Irvine, K., Gale, T.M., 2016. Sex differences in cognitive impairment in Alzheimer's disease. World J. Psychiatry 6, 54-65

Leckie, R.L., Oberlin, L.E., Voss, M.W., Prakash, R.S., Szabo-Reed, A. Chaddock-Heyman, L., Phillips, S.M., Gothe, N.P., Mailey, E., Vieira-Potter, V.J., Martin, S.A., Pence, B.D., Lin, M., Parasuraman, R., Greenwood, P.M., Fryxell, K.J. Woods, J.A., McAuley, E., Kramer, A.F., Erickson, K.I., 2014. BDNF mediates improvements in executive function following a 1-year exercise intervention. Front. Hum. Neurosci. 8, 985.

Leiter, O., Kempermann, G., Walker, T.L., 2016. A common language: how neuroimmunological cross talk regulates adult hippocampal neurogenesis. Stem Cells Int. 2016, 1681590.

Leza, J.C., Garcia-Bueno, B., Bioque, M., Arango, C., Parellada, M., Do, K., O’Donnell, P., Bernardo, M., 2015. Inflammation in schizophrenia: a question of balance. Neurosci. Biobehav. Rev. 55, 612-626.

Lindenberger, U., 2014. Human cognitive aging: corriger la fortune? Science 346 $572-578$

Litteljohn, D., Nelson, E., Hayley, S., 2014. IFN-gamma differentially modulates memory-related processes under basal and chronic stressor conditions. Front. Cell. Neurosci. 8, 391

Louveau, A., Harris, T.H., Kipnis, J., 2015. Revisiting the mechanisms of CNS immune privilege. Trends Immunol. 36, 569-577.

Lu, B., Pang, P.T., Woo, N.H., 2005. The yin and yang of neurotrophin action. Nat. Rev. Neurosci. 6, 603-614.

Lustig, C., Shah, P., Seidler, R., Reuter-Lorenz, P.A., 2009. Aging, training, and the brain: a review and future directions. Neuropsychol. Rev. 19, 504-522.

Müller, L., Pawelec, G., 2014. Aging and immunity-impact of behavioral intervention. Brain Behav. Immun. 39, 8-22.

Müller, L., Pawelec, G., 2015. As we age: does slippage of quality control in the immune system lead to collateral damage? Ageing Res. Rev. 23, 116-123.

Müller, L., Fulop, T., Pawelec, G., 2013. Immunosenescence in vertebrates and invertebrates. Immun. Ageing: I \& A 10, 12.

Maass, A., Duzel, S., Goerke, M., Becke, A., Sobieray, U., Neumann, K., Lovden, M., Lindenberger, U., Backman, L., Braun-Dullaeus, R., Ahrens, D., Heinze, H.J., Muller, N.G., Duzel, E., 2015. Vascular hippocampal plasticity after aerobic exercise in older adults. Mol. Psychiatry 20, 585-593.

Maier, S.F., Goehler, L.E., Fleshner, M., Watkins, L.R., 1998. The role of the vagus nerve in cytokine-to-brain communication. Ann. N. Y. Acad. Sci. 840, 289-300.

Majka, D.S., Chang, R.W., Vu, T.H., Palmas, W., Geffken, D.F., Ouyang, P., Ni, H., Liu, K., 2009. Physical activity and high-sensitivity C-reactive protein: the multi-ethnic study of atherosclerosis. Am. J. Prev. Med. 36, 56-62.

Malaguarnera, L., Cristaldi, E., Malaguarnera, M., 2010. The role of immunity in elderly cancer. Crit. Rev. Oncol. Hematol. 74, 40-60.

Minter, M.R., Moore, Z., Zhang, M., Brody, K.M., Jones, N.C., Shultz, S.R., Taylor, J.M. Crack, P.J., 2016. Deletion of the type-1 interferon receptor in APPSWE/PS1DeltaE9 mice preserves cognitive function and alters glial phenotype. Acta Neuropathol. Commun. 4, 72.
Moylan, S., Eyre, H.A., Maes, M., Baune, B.T., Jacka, F.N., Berk, M., 2013. Exercising the worry away: how inflammation, oxidative and nitrogen stress mediates the beneficial effect of physical activity on anxiety disorder symptoms and behaviours. Neurosci. Biobehav. Rev. 37, 573-584.

Na, K.S., Jung, H.Y., Kim, Y.K., 2014. The role of pro-inflammatory cytokines in the neuroinflammation and neurogenesis of schizophrenia. Prog. Neuropsychopharmacol. Biol. Psychiatry. 48, 277-286.

Naylor, K., Li, G., Vallejo, A.N., Lee, W.W., Koetz, K., Bryl, E., Witkowski, J., Fulbright, J., Weyand, C.M., Goronzy, J.J., 2005. The influence of age on T cell generation and TCR diversity. J. Immunol. 174, 7446-7452.

Ngandu, T., Lehtisalo, J., Solomon, A., Levalahti, E., Ahtiluoto, S., Antikainen, R., Backman, L., Hanninen, T., Jula, A., Laatikainen, T., Lindstrom, J., Mangialasche, F., Paajanen, T., Pajala, S., Peltonen, M., Rauramaa, R., Stigsdotter-Neely, A., Strandberg, T., Tuomilehto, J., Soininen, H., Kivipelto, M., 2015. A 2 year multidomain intervention of diet, exercise, cognitive training, and vascular risk monitoring versus control to prevent cognitive decline in at-risk elderly people (FINGER): a randomised controlled trial. Lancet 385, 2255-2263.

Nimmerjahn, A., Kirchhoff, F., Helmchen, F., 2005. Resting microglial cells are highly dynamic surveillants of brain parenchyma in vivo. Science 308, 1314-1318.

Norden, D.M., Muccigrosso, M.M., Godbout, J.P., 2015. Microglial priming and enhanced reactivity to secondary insult in aging, and traumatic CNS injury, and neurodegenerative disease. Neuropharmacology 96, 29-41.

Norton, S., Matthews, F.E., Barnes, D.E., Yaffe, K., Brayne, C., 2014. Potential for primary prevention of Alzheimer's disease: an analysis of population-based data. Lancet Neurol. 13, 788-794.

Nunes, S.O., Vargas, H.O., Prado, E., Barbosa, D.S., de Melo, L.P., Moylan, S., Dodd, S., Berk, M., 2013. The shared role of oxidative stress and inflammation in major depressive disorder and nicotine dependence. Neurosci. Biobehav. Rev. 37 , 1336-1345.

Oswald, W.D.G., Rupprecht, T., Hagen, R., 2006. Differential effects of single versus combined cognitive and physical training with older adults: the SimA study in a 5-year perspective. Eur. J. Ageing 3.

Ownby, R.L., 2010. Neuroinflammation and cognitive aging. Curr. Psychiatry Rep. $12,39-45$

Papenberg, G., Ferencz, B., Mangialasche, F., Mecocci, P., Cecchetti, R., Kalpouzos, G., Fratiglioni, L., Backman, L., 2016. Physical activity and inflammation: effects on gray-matter volume and cognitive decline in aging. Hum. Brain Mapp.

Patterson, S.L., 2015. Immune dysregulation and cognitive vulnerability in the aging brain: interactions of microglia, IL-1beta, BDNF and synaptic plasticity. Neuropharmacology 96, 11-18.

Pawelec, G., Derhovanessian, E., 2011. Role of CMV in immune senescence. Virus Res. 157, 175-179.

Pawelec, G., Larbi, A., Derhovanessian, E., 2010. Senescence of the human immune system. J. Comp. Pathol. 142 (Suppl. (1)), S39-44.

Pedersen, B.K., Hoffman-Goetz, L., 2000. Exercise and the immune system: regulation, integration, and adaptation. Physiol. Rev. 80, 1055-1081.

Pedersen, B.K., 2011. Exercise-induced myokines and their role in chronic diseases. Brain Behav. Immun. 25, 811-816.

Petersen, A.M., Pedersen, B.K., 2005. The anti-inflammatory effect of exercise. J. Appl. Physiol. 98, 1154-1162, 1985.

Phillips, C., Baktir, M.A., Srivatsan, M., Salehi, A., 2014. Neuroprotective effects of physical activity on the brain: a closer look at trophic factor signaling. Front. Cell. Neurosci. 8, 170.

Pizza, V., Agresta, A., D’Acunto, C.W., Festa, M., Capasso, A., 2011. Neuroinflammation and ageing: current theories and an overview of the data. Rev. Recent Clin. Trials 6, 189-203.

Plata-Salaman, C.R., 1991. Immunoregulators in the nervous system. Neurosci. Biobehav. Rev. 15, 185-215.

Podewils, L.J., Guallar, E., Kuller, L.H., Fried, L.P., Lopez, O.L., Carlson, M., Lyketsos, C.G., 2005. Physical activity, APOE genotype, and dementia risk: findings from the Cardiovascular Health Cognition Study. Am. J. Epidemiol. 161, 639-651.

Prakash, R.S., Voss, M.W., Erickson, K.I., Kramer, A.F., 2015. Physical activity and cognitive vitality. Annu. Rev. Psychol. 66, 769-797.

Prinz, M., Priller, J., Sisodia, S.S., Ransohoff, R.M., 2011. Heterogeneity of CNS myeloid cells and their roles in neurodegeneration. Nat. Neurosci. 14, 1227-1235.

Qi, Q., Liu, Y., Cheng, Y., Glanville, J., Zhang, D., Lee, J.Y., Olshen, R.A., Weyand, C.M., Boyd, S.D., Goronzy, J.J., 2014a. Diversity and clonal selection in the human T-cell repertoire. Proc. Natl. Acad. Sci. U. S. A. 111, 13139-13144.

Qi, Q., Zhang, D.W., Weyand, C.M., Goronzy, J.J., 2014b. Mechanisms shaping the naive $\mathrm{T}$ cell repertoire in the elderly-thymic involution or peripheral homeostatic proliferation? Exp. Gerontol. 54, 71-74.

Quan, N., Banks, W.A., 2007. Brain-immune communication pathways. Brain Behav. Immun. 21, 727-735

Raper, D., Louveau, A., Kipnis, J., 2016. How do meningeal lymphatic vessels drain the CNS? Trends Neurosci. 39, 581-586.

Ritzel, R.M., Crapser, J., Patel, A.R., Verma, R., Grenier, J.M., Chauhan, A., Jellison, E.R., McCullough, L.D., 2016. Age-associated resident memory CD8 T cells in the central nervous system are primed to potentiate inflammation after ischemic brain injury. J. Immunol. 196, 3318-3330.

Ron-Harel, N., Cardon, M., Schwartz, M., 2011. Brain homeostasis is maintained by danger signals stimulating a supportive immune response within the brain's borders. Brain Behav. Immun. 25, 1036-1043.

Salam, N., Rane, S., Das, R., Faulkner, M., Gund, R., Kandpal, U., Lewis, V., Mattoo, H., Prabhu, S., Ranganathan, V., Durdik, J., George, A., Rath, S., Bal, V., 2013. T cell 
ageing: effects of age on development, survival \& function. Indian J. Med. Res. 138, 595-608.

Scheinert, R.B., Asokan, A., Rani, A., Kumar, A., Foster, T.C., Ormerod, B.K., 2015. Some hormone, cytokine and chemokine levels that change across lifespan vary by cognitive status in male Fischer 344 rats. Brain Behav. Immun. 49, 216-232.

Schmiedek, F., Lövdén, M., Lindenberger, U., 2010. Hundred days of cognitive training enhance broad cognitive abilities in adulthood: findings from the COGITO study. Front. Aging Neurosci. 2.

Schnydrig, S., Korner, L., Landweer, S., Ernst, B., Walker, G., Otten, U., Kunz, D., 2007. Peripheral lipopolysaccharide administration transiently affects expression of brain-derived neurotrophic factor, corticotropin and proopiomelanocortin in mouse brain. Neurosci. Lett. 429, 69-73.

Shechter, R., London, A., Varol, C., Raposo, C., Cusimano, M., Yovel, G., Rolls, A., Mack, M., Pluchino, S., Martino, G., Jung, S., Schwartz, M., 2009. Infiltrating blood-derived macrophages are vital cells playing an anti-inflammatory role in recovery from spinal cord injury in mice. PLoS Med. 6, e1000113.

Shechter, R., London, A., Schwartz, M., 2013. Orchestrated leukocyte recruitment to immune-privileged sites: absolute barriers versus educational gates. Nat. Rev. Immunol. 13, 206-218.

Silverman, M.N., Deuster, P.A., 2014. Biological mechanisms underlying the role of physical fitness in health and resilience. Interface Focus 4, 20140040.

Simpson, R.J., 2016. Aging and inflammation: directing traffic through physical activity. Brain Behav. Immun. 56, 10-11.

Singhal, G., Jaehne, E.J., Corrigan, F., Baune, B.T., 2014. Cellular and molecular mechanisms of immunomodulation in the brain through environmental enrichment. Front. Cell. Neurosci. 8, 97.

Snigdha, S., de Rivera, C., Milgram, N.W., Cotman, C.W., 2014. Exercise enhances memory consolidation in the aging brain. Front. Aging Neurosci. 6, 3.

Sparkman, N.L., Johnson, R.W., 2008. Neuroinflammation associated with aging sensitizes the brain to the effects of infection or stress. Neuroimmunomodulation 15, 323-330.

Speisman, R.B., Kumar, A., Rani, A., Foster, T.C., Ormerod, B.K., 2013a. Daily exercise improves memory, stimulates hippocampal neurogenesis and modulates immune and neuroimmune cytokines in aging rats. Brain Behav. Immun. 28, 25-43.

Speisman, R.B., Kumar, A., Rani, A., Pastoriza, J.M., Severance, J.E., Foster, T.C., Ormerod, B.K., 2013b. Environmental enrichment restores neurogenesis and rapid acquisition in aged rats. Neurobiol. Aging 34, 263-274.

Stellwagen, D., Malenka, R.C., 2006. Synaptic scaling mediated by glial TNF-alpha. Nature 440, 1054-1059.

Stolp, H.B., Liddelow, S.A., Sa-Pereira, I., Dziegielewska, K.M., Saunders, N.R., 2013. Immune responses at brain barriers and implications for brain development and neurological function in later life. Front. Integr. Neurosci. 7, 61.

Swardfager, W., Rosenblat, J.D., Benlamri, M., McIntyre, R.S., 2016. Mapping inflammation onto mood: inflammatory mediators of anhedonia. Neurosci. Biobehav. Rev. 64, 148-166.

Szuhany, K.L., Bugatti, M., Otto, M.W., 2015. A meta-analytic review of the effects of exercise on brain-derived neurotrophic factor. J. Psychiatr. Res. 60, 56-64.

Tansey, M.G., Goldberg, M.S., 2010. Neuroinflammation in Parkinson's disease: its role in neuronal death and implications for therapeutic intervention. Neurobiol. Dis. 37, 510-518.

Tansey, M.G., 2010. Inflammation in neuropsychiatric disease. Neurobiol. Dis. 37, 491-492.

Tay, T.L., Savage, J., Hui, C.W., Bisht, K., Tremblay, M.E., 2016. Microglia across the lifespan: from origin to function in brain development, plasticity and cognition. J. Physiol.

Timmerman, K.L., Flynn, M.G., Coen, P.M., Markofski, M.M., Pence, B.D., 2008. Exercise training-induced lowering of inflammatory (CD14 + CD16 +) monocytes: a role in the anti-inflammatory influence of exercise. J. Leukoc. Biol. 84, 1271-1278.

Tolppanen, A.M., Solomon, A., Kulmala, J., Kareholt, I., Ngandu, T., Rusanen, M., Laatikainen, T., Soininen, H., Kivipelto, M., 2015. Leisure-time physical activity from mid- to late life, body mass index, and risk of dementia. Alzheimer's Demen. 11, 434-443, e436.

Tumati, S., Burger, H., Martens, S., van der Schouw, Y.T., Aleman, A., 2016. Association between cognition and serum insulin-like growth factor-1 in middle-aged \& older men: an 8 year follow-up study. PLoS One 11, e0154450.

Turner, J.E., 2016. Is immunosenescence influenced by our lifetime dose of exercise? Biogerontology 17, 581-602.

Varma, V.R., Chuang, Y.F., Harris, G.C., Tan, E.J., Carlson, M.C., 2015. Low-intensity daily walking activity is associated with hippocampal volume in older adults. Hippocampus 25, 605-615.
Vaupel, J.W., Carey, J.R., Christensen, K., 2003. Aging. It's never too late Science 301, 1679-1681.

Vegeto, E., Benedusi, V., Maggi, A., 2008. Estrogen anti-inflammatory activity in brain: a therapeutic opportunity for menopause and neurodegenerative diseases. Front. Neuroendocrinol. 29, 507-519.

Veiga-Fernandes, H., Mucida, D., 2016. Neuro-immune interactions at barrier surfaces. Cell 165, 801-811.

Vescovini, R., Fagnoni, F.F., Telera, A.R., Bucci, L., Pedrazzoni, M., Magalini, F., Stella, A., Pasin, F., Medici, M.C., Calderaro, A., Volpi, R., Monti, D., Franceschi, C., Nikolich-Zugich, J., Sansoni, P., 2014. Naive and memory CD8 T cell pool homeostasis in advanced aging: impact of age and of antigen-specific responses to cytomegalovirus. Age (Dordr) 36, 625-640.

Villeda, S.A., Luo, J., Mosher, K.I., Zou, B., Britschgi, M., Bieri, G., Stan, T.M., Fainberg, N., Ding, Z., Eggel, A., Lucin, K.M., Czirr, E., Park, J.S., Couillard-Despres, S., Aigner, L., Li, G., Peskind, E.R., Kaye, J.A., Quinn, J.F., Galasko, D.R., Xie, X.S., Rando, T.A., Wyss-Coray, T., 2011. The ageing systemic milieu negatively regulates neurogenesis and cognitive function. Nature 477, 90-94.

Wekerle, H., 2006. Breaking ignorance: the case of the brain. Curr. Top. Microbiol. Immunol. 305, 25-50.

Willis, S.L., Tennstedt, S.L., Marsiske, M., Ball, K., Elias, J., Koepke, K.M., Morris, J.N., Rebok, G.W., Unverzagt, F.W., Stoddard, A.M., Wright, E., Group, A.S., 2006. Long-term effects of cognitive training on everyday functional outcomes in older adults. JAMA 296, 2805-2814.

Wilson, C.J., Finch, C.E., Cohen, H.J., 2002. Cytokines and cognition?the case for a head-to-toe inflammatory paradigm. J. Am. Geriatr. Soc. 50, 2041-2056.

Wirth, M., Haase, C.M., Villeneuve, S., Vogel, J., Jagust, W.J., 2014. Neuroprotective pathways: lifestyle activity, brain pathology, and cognition in cognitively normal older adults. Neurobiol. Aging 35, 1873-1882.

Wistuba-Hamprecht, K., Haehnel, K., Janssen, N., Demuth, I., Pawelec, G., 2015. Peripheral blood T-cell signatures from high-resolution immune phenotyping of gammadelta and alphabeta T-cells in younger and older subjects in the Berlin Aging Study II. Immun. Ageing: I \& A 12, 25.

Wohleb, E.S., Delpech, J.C., 2016. Dynamic cross-talk between microglia and peripheral monocytes underlies stress-induced neuroinflammation and behavioral consequences. Prog. Neuropsychopharmacol. Biol. Psychiatry.

Wolf, S.A., Steiner, B., Akpinarli, A., Kammertoens, T., Nassenstein, C., Braun, A., Blankenstein, T., Kempermann, G., 2009. CD4-positive T lymphocytes provide a neuroimmunological link in the control of adult hippocampal neurogenesis. J. Immunol. 182, 3979-3984.

Xie, L., Choudhury, G.R., Winters, A., Yang, S.H., Jin, K., 2015. Cerebral regulatory T cells restrain microglia/macrophage-mediated inflammatory responses via IL-10. Eur. J. Immunol. 45, 180-191.

Yaffe, K., Barnes, D., Nevitt, M., Lui, L.Y., Covinsky, K., 2001. A prospective study of physical activity and cognitive decline in elderly women: women who walk. Arch. Intern. Med. 161, 1703-1708.

Yau, S.Y., Lau, B.W., So, K.F., 2011. Adult hippocampal neurogenesis: a possible way how physical exercise counteracts stress. Cell Transplant. 20, 99-111.

Yau, S.Y., Li, A., So, K.F., 2015. Involvement of adult hippocampal neurogenesis in learning and forgetting. Neural Plast. 2015, 717958.

Ye, S.M., Johnson, R.W., 1999. Increased interleukin-6 expression by microglia from brain of aged mice. J. Neuroimmunol. 93, 139-148.

Yirmiya, R., Goshen, I., 2011. Immune modulation of learning, memory, neural plasticity and neurogenesis. Brain Behav. Immun. 25, 181-213.

Zagni, E., Simoni, L., Colombo, D., 2016. Sex and gender differences in central nervous system-related disorders. Neurosci. J. 2016, 2827090.

Ziv, Y., Ron, N., Butovsky, O., Landa, G., Sudai, E., Greenberg, N., Cohen, H., Kipnis, J., Schwartz, M., 2006. Immune cells contribute to the maintenance of neurogenesis and spatial learning abilities in adulthood. Nat. Neurosci. 9, 268-275.

de Pablo-Bernal, R.S., Canizares, J., Rosado, I., Galva, M.I., Alvarez-Rios, A.I., Carrillo-Vico, A., Ferrando-Martinez, S., Munoz-Fernandez, M.A., Rafii-El-Idrissi Benhnia, M., Pacheco, Y.M., Ramos, R., Leal, M., Ruiz-Mateos, E., 2016. Monocyte phenotype and polyfunctionality are associated with elevated soluble inflammatory markers, cytomegalovirus infection, and functional and cognitive decline in elderly adults. J. Gerontol. A. Biol. Sci. Med. Sci. 71, 610-618.

von Bernhardi, R., Tichauer, J.E., Eugenin, J., 2010. Aging-dependent changes of microglial cells and their relevance for neurodegenerative disorders. J. Neurochem. 112, 1099-1114. 